Proceedings of the Institution for Mechanical Engineers-

Part N: Journal of Nanomaterials, Nanoengineering and Nanosystems

Accepted March 24 2019

ISSN: 2397-7914; Online ISSN: 2397-7922. Publisher- Sage

\title{
COMPUTATIONAL STUDY OF UNSTEADY COUPLE STRESS MAGNETIC NANOFLUID FLOW FROM A STRETCHING SHEET WITH OHMIC DISSIPATION
}

\author{
Mahesh Kumar ${ }^{1}$, G. Janardhana Reddy ${ }^{1, *}$, N. Naresh Kumar² and O. Anwar Bég ${ }^{3}$ \\ ${ }^{l}$ Department of Mathematics, Central University of Karnataka, Kalaburagi, India. \\ ${ }^{2}$ School of Humanities \& Sciences, Sastra Deemed University, Tamil Nadu, India \\ ${ }^{3}$ Aeronautical \& Mechanical Engineering Department, Salford University, M54WT, UK \\ "Corresponding author- Email: gjr@cuk.ac.in
}

\begin{abstract}
To provide a deeper insight of the transport phenomena inherent to the manufacturing of magnetic nano-polymer materials, in the present work a mathematical model is developed for time-dependent hydromagnetic rheological nanopolymer boundary layer flow and heat transfer over a stretching sheet in the presence of a transverse static magnetic field. Joule heating (Ohmic dissipation) and viscous heating effects are included since these phenomena arise frequently in magnetic materials processing. Stokes' couple stress model is deployed to simulate non-Newtonian micro-structural characteristics. The Tiwari-Das nanoscale model is adopted which permits different nano-particles to be simulated (in this article both copper-water and aluminium oxide-water nanofluids are considered). Similarity transformations are utilized to convert the governing partial differential conservation equations into a system of coupled, nonlinear ordinary differential equations with appropriate wall and free stream boundary conditions. The shooting technique is used to solve the reduced nonlinear coupled ordinary differential boundary value problem via MATLAB symbolic software. Validation with published results from the literature is included for the special cases of non-dissipative and Newtonian nanofluid flows. Fluid velocity and temperature profiles for both Copper and Aluminium Oxide $\left(\mathrm{Al}_{2} \mathrm{O}_{3}\right)$ nanofluids are observed to be enhanced with greater non-Newtonian couple stress parameter and magnetic parameter whereas the opposite trend is computed with greater values of unsteadiness parameter. The boundary layer flow is accelerated with increasing buoyancy parameter, elastic sheet stretching parameter and convection parameter. Temperatures are generally increased with greater couple stress rheological parameter and are consistently higher for the Aluminium oxide nanoparticle case. Temperatures are also boosted with magnetic parameter and exhibit an overshoot near the wall when magnetic parameter exceeds unity (magnetic force exceeds viscous force). A decrease in temperatures is induced with increasing sheet stretching parameter. Increasing Eckert number elevates temperatures considerably. With greater nanoparticle volume fraction both skin friction and Nusselt number are elevated and copper nano-particles achieve higher magnitudes than aluminium oxide.
\end{abstract}

KEYWORDS: Couple stress fluid; Nano-polymer; Tiwari-Das model; Shooting Method; Stretching sheet; Heat transfer; Boundary layers; Buoyancy; Ohmic dissipation; Magnetic nano-materials processing. 


\section{INTRODUCTION}

Nano-polymer materials are finding ever-increasing applications in coating systems for medical and industrial systems. Nano-polymers belong to the group of nanotechnological materials known as "nanofluids" which were introduced by Choi [1] in the 1990s. They were designed by suspending nano-scale particles in the base fluid to enhance the heat transfer efficiency of engineering fluids [2]. The addition of small fractions of nanoparticles (copper, copper oxide, aluminium oxide, silver etc.) has been shown to significantly enhance the thermal conductivity [3]. Water-based polymeric nanofluids have been extensively studied in recent years both with metallic [4] and non-metallic nano-particles [5]. Aluminium Oxide $\left(\mathrm{Al}_{2} \mathrm{O}_{3}\right)$ is the most widely used nanoparticle and it can be acquired in sizes as low as $40 \mathrm{~nm}$. Furthermore, several investigators have used Aluminium Oxide nano-particles in for example the so-called "top-down" approach of microfabrication methods, micro-patterning techniques e.g. photolithography and inkjet printing, in gear manufacturing surface treatment etc. Similarly, Copper $(\mathrm{Cu})$ nanoparticles are also remarkable due to the inherent high thermal and electric conductivities. It ensures multi-functional assets with applications such as frictional brake components, electrode materials, industrial spot welding etc. The thermal conductivity of $\mathrm{Cu}$ is $401 \mathrm{~W} / \mathrm{mK}$ and it is therefore frequently deployed to achieve significant elevation in thermal conductivity of base fluids. Further details concerning the synthesis, selection and implementation of $\mathrm{Al}_{2} \mathrm{O}_{3}$ and $\mathrm{Cu}$ nanoparticles in industrial systems are documented in [6-8]. Another sub-group of nanofluids known as magnetic nano-polymers has also emerged in recent years. Such nanoscale "smart" materials feature polymer base fluids doped with magnetic nano-particles and during manufacture (and in operation) their material characteristics can be successfully manipulated by magnetic fields and also heat (thermal treatment). These materials offer significant advantages in numerous areas of technology including dampers for aerospace and earthquake protection, cooling, lubrication, anti-corrosion resistance, anti-abrasive solar collector film coatings etc. Examples of magnetic nanofluids include water-based thixotropic polymer gel electrolytes [9], magnetic water-soluble cyano-bridged metallic nano-polymers [10] and organo-metallic nano functional copolymers (utilizing combinations of high aluminum concentrations, aqueous solution and nano chelating resins) [11]. A number of studies describing the benefits of magnetic nano-polymers have been communicated in diverse areas including energy [12] in which they can be exploited for working fluids, coatings, heat dissipation, tribology etc. Magnetic nano-particles have been shown experimentally to achieve thermal conductivity enhancement via magnetic field induced chain-like nanoparticles aggregation [13]. With judicious selection of externally applied magnetic field it has been found that significant improvement in heat transfer characteristics is attained with magnetized 
nanofluids since they modify nanolayer conductivity [14] and this can be optimized with careful specification of the nanoparticle type (e.g. metallic, graphene etc) [15] and size. Techniques for producing stable, durable and efficient magnetic nanofluids have been described in [16]. Mathematical models of magnetic nanofluid transport combine the science of magnetohydrodynamics (MHD) with nano-scale behaviour. The electrically-conducting nature of magnetic nanofluids allow the simultaneous advantages of flow control and thermal enhancement. Magnetic nanomaterial thermal flow simulation was described in detailed by Uddin et al. [17] using the Buongiorno nanoscale model which highlights Brownian diffusion and thermophoresis. Further details of magnetic phenomena associated with the performance of magnetite nanofluids have been provided by Dekker [18] and Bao et al. [19].

Another important characteristic of magnetic nanofluids is non-Newtonian behaviour. The presence of nano-particles has been found to achieve greater stability of viscosity at higher temperature which is associated with the rheology of magnetic nano-polymers [20]. Magneto-rheological nanopolymers can be deployed in many diverse applications including petroleum drilling, smart actuation systems, optics finishing, fluid clutches, aerospace sealing etc. Iron-Nickel magnetic nano-polymer fluids have been studied in detail by Katiyar et al. [21] who observed significant improvement in viscosity control via nano-particle doping and magnetic field application and a resulting significant enhancement in yield stress. Other interesting studies of rheology of magnetic nanofluids and nanopolymers have been presented by Sharma et al. [22] who considered viscoplastic characteristics of silica-nano-particle-based nano-polymers (using Bingham plastic and Herschel-Bulkley models) and Hojjat et al. [23] who explored pseudoplastic (shear thinning) behaviour associated with Titanium oxide magnetic nano-polymers. Viscoelastic characteristics of electro-conductive nano-polymers were described by Yang et al. [24]. Tribological and viscosity improvements in zinc and copperoxide nano-doped viscoplastic nanofluids were experimentally confirmed by Bég et al. [25]. Very recently Bég et al. [26] investigated numerically the viscosity modification via nano-particle volume fraction tuning in nano-polymer rheological coatings for solar applications.

From a materials processing perspective, the analysis of the flow driven by a stretching surface is of fundamental importance. It features in glass crystal growing, continuous stretching, fibre drawing and artificial fibers, rolling and manufacturing of plastic film, plastic extrusion, drawing of copper wires, cooling of an infinite metallic sheet, annealing and tinning of copper wires, coating of components etc. Analytical studies of the flow of viscous (Newtonian) fluid along a continuous 
moving sheet were initiated in the context of polymer materials processing by Sakiadis [27]. Rajagopal and Gupta [28] extended the Sakiadis model to consider viscoelastic rheological fluids. Khan and Shehzad [29] explored Sisko flow from a stretching sheet. Mahmoud and Megahed [30] considered the Ostwald-DeWaele power-law fluid in stretching sheet flows. Bachok et al. [31] examined the heat transfer stagnation-point flow from an exponential stretching sheet in nanofluid. They considered three different nanoparticles with water base fluid and analysed heat transfer characteristics thoroughly. Hayat et al. [32] made the comparative study of MHD viscous fluid from stretching sheet in porous medium by means of $\mathrm{Cu}, \mathrm{Ag}, \mathrm{Al}_{2} \mathrm{O}_{3}$ and $\mathrm{TiO}_{2}$ nanoparticles with water as base fluid. Anajli and Suriya [33] analysed the hydromagnetic flow from a permeable stretching sheet by considering two different hybrid nanoparticles. They concluded that heat transfer rate of $\mathrm{Cu}-$ $\mathrm{Al}_{2} \mathrm{O}_{3}$ /water nanofluid is higher that $\mathrm{Cu} /$ water nanofluid. In many stretching flows, transient behaviour is induced due to a sudden stretching of the flat sheet. This arises in for example the flow from an impulsive stretching of the sheet or the flow induced by a step change of the temperature. When the surface is stretched suddenly with a definite velocity, the flow is developed instantaneously. An important investigation of transient stretching flows has been conducted by Wang et al. [34] although for non-conducting Newtonian fluids. Tarakaramu and Narayana [35] studied the similar transient flow problem for three distinct water-based nanofluids with magnetohydrodynamic and chemical reaction effects. Recently, Hussanan et al. [36] analysed the non-Newtonian micropolar fluid convection from a stretching sheet with magnetite nanoparticles. The rheological models considered above have ignored microstructure. The classical non-Newtonian models (viscoplastic, viscoelastic, thixotropic etc) are non-polar and cannot properly simulate suspended particles. They have therefore limited relevance to nanofluid dynamics. Amongst nonNewtonian fluids, the Stokes couple stress fluid [37] provides an elegant framework for microstructural polymer flows. Couple stresses appear in noticeable magnitudes in liquids with very large molecules such as polymer solutions, slurries, nano-lubricants, coolants, propellants and biological liquids etc. Couple stress flows have been simulated by a number of researchers. Khan et al. [38] obtained computational solutions for couple stress thermal convection boundary layer flow on a stretching sheet for both prescribed surface temperature and prescribed heat flux cases with a fourth order Runge-Kutta method. Ramana Murthy et al. [39] used a homotopy method to analyse the entropy generation in couple stress channel flows with convection and radiation heat transfer. 
Hayat et al. [40] investigated numerically the reactive couple stress flow with heat and mass transfer from a stretching surface. Tripathi et al. [41] studied the peristaltic pumping of electro-kinetic couple stress fluids in microchannel configurations. These studies all confirmed the significant modification to flow and thermal characteristics induced by couple stresses. In recent years some interest in couple stress nanofluid mechanics has also emerged, primarily in terms of numerical simulation. These studies have considered both non-magnetic and magnetic nanofluids. Awais et al. [42] employed an optimal homotopy method to compute the magnetic couple-stress nanofluid flow over a moving convective wall. Makinde and Eegunjobi [43] analysed the impact of thermal radiation on entropy generation in couple stress magnetic nanofluid flow in a channel with wall suction/injection effects. Awad et al. [44] used a spectral relaxation method to consider time-dependent couple stress nanofluid flow from a stretching sheet with passive control of the nanoparticle volume fraction at the boundary. Chand et al. [45] conducted a linear stability analysis for the onset of convection of rotating couplestress nanofluid in a porous medium using the Buongiorno nanoscale model. Rehman et al. [46] studied boundary layer stagnation point flow and heat transfer of couple stress nanofluid flow over an exponentially stretching surface in a porous medium.

In the present work, a theoretical and numerical study of the unsteady convective flow of a couple stress magnetic nanofluid (water-based magnetic nano-polymer) from a stretching surface is considered. Two nanoparticles i.e. copper $(\mathrm{Cu})$ and alumina $\left(\mathrm{Al}_{2} \mathrm{O}_{3}\right)$. These kinds of nanoparticles over an industrial scale lead to more dimensional stability, are more ecologically friendly and can be successfully well-dispersed in the base fluids. The thermal conductivity of these nanoparticles is much higher than the base fluids, and nanofluids prepared with these particles are known to achieve excellent thermal enhancement. Both viscous and Joule heating (Ohmic dissipation) are included. Ohmic dissipation has been shown to be significant in magnetic polymer materials processing as elaborated earlier in Shamshuddin et al. [47], Sahoo [48] and Zueco et al. [49]. It has also been considered more recently in electromagnetic nanofluids as described by Tripathi et al. [50], Ghadikolaei et al. [51], Hussain et al. [52], Shagaiy et al. [53] and Nandkeolyar et al. [54]. The Tiwari-Das [55] nanoscale volume fraction model is adopted which permits different nano-particles to be simulated (in this article both copper-water and aluminium oxide-water nanofluids are considered). Transient stretching of the sheet is considered [56]. Computational solutions are obtained for the nonlinear dimensionless boundary value problem using a shooting technique via MATLAB symbolic software [57]. Validation with published results from the literature is included for the special cases of non-dissipative and Newtonian nanofluid flows. Extensive visualization of 
velocity, temperature skin friction and Nusselt number distributions are presented. The present work aims to provide a deeper insight into the thermo-fluid characteristics of rheological magnetic nanomaterials processing and has not been reported thus far in the technical literature.

\section{MATHEMATICAL FORMULATION}

Time-dependent, two-dimensional, laminar, incompressible couple stress magnetic nano-polymer flow and thermal convection heat transfer from a stretching sheet is considered as depicted in Fig. 1. At the outset i.e., $t=0$, the sheet is impulsively stretched with velocity $U_{w}(x, t)$ along the upward $x$ axis, keeping the origin fixed in the magnetic nanofluid which has a free stream temperature $T_{\infty}$. The temperature of the sheet $T_{w}(x, t)$ is assumed to be a linear function of the $x$-coordinate. A transverse static magnetic field $\left(B_{0}\right)$ is applied. Viscous dissipation and Joule heating (Ohmic dissipation) are incorporated. A fixed Cartesian coordinate scheme is adopted with the origin positioned at the foremost verge of the sheet (slit where the sheet emerges) with the positive $x$-axis extending along the upward direction of sheet and the $y$-axis orientated normal to the surface of the sheet. Under these assumptions (with the boundary layer and Boussinesq's approximations), the governing equations for the mass, momentum and energy conservation in mixed convective flow and heat transfer of the couple stress magnetic nanofluid, obtained by the inclusion of couple stress and magnetic body force terms are:

$$
\begin{gathered}
\frac{\partial u}{\partial x}+\frac{\partial v}{\partial y}=0 \\
\rho_{n f}\left(\frac{\partial u}{\partial t}+u \frac{\partial u}{\partial x}+v \frac{\partial u}{\partial y}\right)=g\left(\rho \beta_{T}\right)_{n f}\left(T-T_{\infty}\right)+\mu_{n f} \frac{\partial^{2} u}{\partial y^{2}}-\eta_{1} \frac{\partial^{4} u}{\partial y^{4}}-\sigma_{n f} B_{0}^{2} u \\
\frac{\partial T}{\partial t}+u \frac{\partial T}{\partial x}+v \frac{\partial T}{\partial y}=\frac{k_{n f}}{\left(\rho C_{p}\right)_{n f}} \frac{\partial^{2} T}{\partial y^{2}}+\frac{1}{\left(\rho C_{p}\right)_{n f}} \sigma_{n f} B_{0}^{2} u^{2}+\frac{\mu_{n f}}{\left(\rho C_{p}\right)_{n f}}\left(\frac{\partial u}{\partial y}\right)^{2}+\frac{\eta_{1}}{\left(\rho C_{p}\right)_{n f}}\left(\frac{\partial^{2} u}{\partial y^{2}}\right)^{2}
\end{gathered}
$$

The associated boundary conditions at the wall (sheet) and in the free stream are given by:

$$
\begin{gathered}
T=T_{w}, v=0, u=U_{w} \quad \text { at } y=0 \\
T \rightarrow T_{\infty}, u \rightarrow 0 \quad \text { as } y \rightarrow \infty \\
\frac{\partial^{2} u}{\partial y^{2}}=0 \text { at } y=0, u \rightarrow 0 \text { and } \frac{\partial u}{\partial y} \rightarrow 0 \text { as } y \rightarrow \infty
\end{gathered}
$$


We assume that the sheet stretching velocity $U_{w}(x, t)$ and the surface temperature $T_{w}(x, t)$ are of the form:

$$
U_{w}(x, t)=\frac{a x}{(1-c t)} \text { and } T_{w}(x, t)=T_{\infty}+\frac{b x}{(1-c t)^{2}}
$$

$\sigma_{n f}$ is effective electrical conductivity of nanofluid, $\rho_{n f}$ is effective density, $\mu_{n f}$ is the effective dynamic viscosity, $\left(\rho C_{p}\right)_{n f}$ is heat capacitance and $k_{n f}$ thermal conductivity of the nanofluid. These physical quantities are based on the Tiwari-Das nanoscale volume fraction model [55] and are mathematically described by:

$$
\begin{gathered}
\rho_{n f}=(1-\phi) \rho_{f}+\phi \rho_{s} \\
\mu_{n f}=\frac{\mu_{f}}{(1-\phi)^{2.5}} \\
\beta_{n f}=(1-\phi) \beta_{f}+\phi \beta_{s} \\
\left(\rho C_{p}\right)_{n f}=(1-\phi)\left(\rho C_{p}\right)_{f}+\phi\left(\rho C_{p}\right)_{s} \\
\sigma_{n f}=\sigma_{f}\left[1+\frac{3\left\{\frac{\sigma_{s}}{\sigma_{f}}-1\right\} \phi}{\left\{\frac{\sigma_{s}}{\sigma_{f}}+2\right\}-\left\{\frac{\sigma_{s}}{\sigma_{f}}-1\right\} \phi}\right]
\end{gathered}
$$

The model deployed for the effective thermal conductivity of the nanofluid, is the Hamilton-Crosser model [14] which is incorporated in the Tiwari-Das formulation [55]:

$$
k_{n f}=k_{f}\left[\frac{k_{s}+(m-1) k_{f}-(m-1)\left(k_{f}-k_{S}\right) \phi}{k_{S}+(m-1) k_{f}+\left(k_{f}-k_{s}\right) \phi}\right]
$$

where $k_{s}, k_{f}$, represent the conductivities of the nanoparticles and base fluid (Newtonian fluid), $m$ designates the nanoparticle shape factor and $\phi$ is the nanoparticle volume fraction. Values of thermophysical properties [58-60] for the base fluid (Newtonian fluid), and different nano-particles obtained with the Tiwari-Das model are summarized in Table 1. 
Table1: Thermophysical properties of base fluids and nanoparticles.

\begin{tabular}{|c|c|c|c|c|c|}
\hline Materials & $\rho\left(\mathrm{kg} \mathrm{m}^{-3}\right)$ & $C_{p}\left(\mathrm{~J} \mathrm{~kg}^{-1} \mathrm{~K}^{-1}\right)$ & $k\left(W m^{-1} K^{-1}\right)$ & $\sigma(\Omega \mathbf{m})^{-1}$ & $\boldsymbol{\beta}\left(\mathbf{K}^{-1}\right)$ \\
\hline Water & 997 & 4179 & 0.613 & $5.5 \times 10^{-5}$ & $21 \times 10^{6}$ \\
\hline $\mathrm{Cu}$ & 8933 & 385 & 401 & $596 \times 10^{6}$ & $1.67 \times 10^{6}$ \\
\hline $\mathrm{Al}_{2} \mathrm{O}_{3}$ & 3970 & 765 & 40 & $35 \times 10^{6}$ & $0.85 \times 10^{5}$ \\
\hline
\end{tabular}

Progressing with the analysis, let us introduce the following dimensionless stream function, $f$, and temperature function, $\theta$, and similarity variable, $\eta$, as follows [61]:

$$
\eta=\sqrt{\frac{a}{v(1-c t)}} y, \psi=\sqrt{\frac{a v}{(1-c t)}} x f(\eta), \theta(\eta)=\frac{T-T_{\infty}}{T_{w}-T_{\infty}}
$$

Here $\psi(x, y, t)$ is the dimensional stream function defined as $(u, v)=\left(\frac{\partial \psi}{\partial y},-\frac{\partial \psi}{\partial x}\right)$ which identically satisfies the continuity (mass conservation) equation (1). Substituting Eqn. (12) into (2) and (3) we obtain the reduced self-similar momentum and energy conservations equations:

$$
\begin{aligned}
& \beta f^{v}-f^{\prime \prime \prime}+(1-\phi)^{2.5} K_{1}\left[f^{\prime 2}-f f^{\prime \prime}+A\left(\frac{1}{2} \eta f^{\prime \prime}+f^{\prime}\right)\right]+B_{1} M(1-\phi)^{2.5} f^{\prime} \\
& -(1-\phi)^{2.5} K_{1} K_{2} \lambda \theta=0
\end{aligned}
$$

$\frac{K_{4}}{K_{3} P r} \theta^{\prime \prime}+f \theta^{\prime}-\theta f^{\prime}-A\left(\frac{1}{2} \eta \theta^{\prime}+2 \theta\right)+\frac{1}{K_{3}} B_{1} M E c f^{\prime 2}+\frac{E c}{(1-\phi)^{2.5} K_{3}} f^{\prime \prime 2}+\frac{\beta E c}{K_{3}} f^{\prime \prime \prime 2}=0$,

Here prime denotes differentiation with respect to $\eta, \beta=a \eta_{1} / v^{2} \rho_{f}(1-c t)$ is the couple stress (non-Newtonian) parameter, $A=c / a$ is the unsteadiness parameter, $\operatorname{Pr}=v / \alpha_{f}$ is the Prandtl number, $M=\frac{\sigma_{f} B_{0}^{2}(1-c t)}{a \rho_{f}}$ is the magnetic parameter, $E c=\frac{U_{w}{ }^{2}}{\left(C_{p}\right)_{f}\left(T_{w}-T_{\infty}\right)}$ is the Eckert number, $\lambda=$ $G r / R e^{2}$ is the buoyancy parameter (where $G r=\frac{g\left(\beta_{T}\right)_{f}\left(T_{w}-T_{\infty}\right) x^{3}}{v^{2}}$ denotes local Grashof number and $R e=U_{w} x / v$ denotes the local Reynolds number). Here $\lambda$ is dimensionless constant with $\lambda<0$ and $\lambda>0$ associated respectively with opposing flow and assisting flow cases, whereas $\lambda=0$ relates to the forced convection flow situation (vanishing buoyancy force). The values of $K_{1}, K_{2}, K_{3}, K_{4}$ and $B_{1}$ featured in Eqns. (13) and (14) are defined as:

$$
K_{1}=(1-\phi)+\phi \frac{\rho_{s}}{\rho_{f}}, \quad K_{2}=(1-\phi)+\phi \frac{\beta_{s}}{\beta_{f}}, \quad K_{3}=(1-\phi)+\phi \frac{\left(\rho C_{p}\right)_{s}}{\left(\rho C_{p}\right)_{f}}
$$


$K_{4}=\left[\frac{k_{s}+(m-1) k_{f}-(m-1)\left(k_{f}-k_{s}\right) \phi}{k_{S}+(m-1) k_{f}+\left(k_{f}-k_{S}\right) \phi}\right], \quad B_{1}=\left[\frac{\left(\sigma_{s}+2 \sigma_{f}\right)+2\left(\sigma_{s}-\sigma_{f}\right) \phi}{\left(\sigma_{s}+2 \sigma_{f}\right)-\left(\sigma_{s}-\sigma_{f}\right) \phi}\right]$

The boundary conditions transform to:

$$
\begin{array}{cc}
f(0)=0, f^{\prime}(0)=1, f^{\prime \prime \prime}(0)=0, \theta(0)=1 & \text { at } \eta=0 \\
f^{\prime}(\eta) \rightarrow 0, f^{\prime \prime}(\eta) \rightarrow 0, \theta(\eta) \rightarrow 0 & \text { as } \eta \rightarrow \infty
\end{array}
$$

The local skin-friction coefficient $C_{f}$ and local Nusselt number $N u$ are important wall gradient characteristics associated with thermal rheological materials processing. They are defined as follows:

The surface shear stress $\tau_{\mathrm{w}}$ is given by:

$$
\tau_{w}=\left(\mu_{n f}\left(\frac{\partial u}{\partial y}\right)-\eta_{1}\left(\frac{\partial^{3} u}{\partial y^{3}}\right)\right)_{y=0}
$$

Using similarity transformation from Eq. (6), the shear stress $\tau_{\mathrm{w}}$ becomes

$$
\tau_{w}=v \sqrt{\frac{a}{(1-c t)}} \frac{a x}{(1-c t)}\left(\frac{1}{(1-\varphi)^{2.5}} f^{\prime \prime}(0)-\frac{a \eta_{1}}{\rho v^{2}(1-c t)} f^{\prime \prime \prime \prime}(0)\right)
$$

The local skin-friction coefficient $C_{f}$ is given by

$$
C_{f}=\frac{\tau_{w}}{\rho U_{w}^{2} / 2}, \quad \frac{1}{2} C_{f} R e^{1 / 2}=\frac{1}{(1-\varphi)^{2.5}} f^{\prime \prime}(0)-\beta f^{\prime \prime \prime \prime}(0)
$$

The Nusselt number is defined as follows:

$$
N u=\frac{q_{w}}{T_{w}-T_{\infty}}\left(\frac{x}{k_{f}}\right), q_{w}=-k_{n f}\left(\frac{\partial T}{\partial y}\right)_{y=0} \text { then } N u / R e^{1 / 2}=-\left(\frac{k_{n f}}{k_{f}}\right) \theta^{\prime}(0)
$$

\section{NUMERICAL SOLUTION AND VALIDATION}

The governing non-linear coupled boundary value problem (BVP) defined by Eqns. (13)-(14) and subjected to boundary conditions Eqn. (16) has been solved numerically via a shooting method [57] with the aid of fourth order Runge-Kutta algorithm. The step size is taken as $\Delta \eta=0.1$ and the convergence criteria is set to $10^{-6}$. The methodology is as follows. Using the notation $f=y_{1}$, and $\theta=y_{6}$. Further let $f^{\prime}=y_{1}^{\prime}$ be represented by $y_{2}, f^{\prime \prime}=y_{2}^{\prime}$ by $y_{3}, f^{\prime \prime \prime}=y_{3}^{\prime}$ by $y_{4}$ and $f^{i v}=y_{4}^{\prime}$ by $y_{5}$. The resulting system of ordinary differential equations (ODEs) emerges:

$y_{1}^{\prime}=y_{2}, y_{2}^{\prime}=y_{3}, y_{3}^{\prime}=y_{4}, y_{4}^{\prime}=y_{5}$, 
$y^{\prime}{ }_{5}=(1 / \beta)\left(K_{1} K_{2} \lambda y_{6}+\frac{y_{4}}{(1-\phi)^{2.5}}-M B_{1} y_{2}-K_{1}\left[y_{2}{ }^{2}-y_{1} y_{3}+A\left(\frac{1}{2} \eta y_{3}+y_{2}\right)\right]\right)$

$y_{6}^{\prime}=y_{7}$

$y_{7}^{\prime}=\operatorname{Pr}\left(\frac{K_{3}}{K_{4}}\right)\left(A\left(\frac{1}{2} \eta y_{7}+2 y_{6}\right)+y_{2} y_{6}-y_{1} y_{7}-\frac{1}{K_{3}} E c B_{1} M y_{2}{ }^{2}-\frac{E c}{(1-\phi)^{2.5} K_{3}} y_{3}^{2}-\frac{\beta E c}{K_{3}} y_{4}^{2}\right)$

The corresponding boundary conditions assume the form:

$y_{1}(0)=0, y_{2}(0)=1, y_{3}(0)=$ unknown, $y_{4}(0)=0$,

$y_{5}(0)=$ unknown, $y_{6}(0)=1, y_{7}(0)=$ unknown

$y_{2}(\infty)=0, y_{3}(\infty)=0, y_{6}(\infty)=0$,

In order to integrate Eqns. (21a) - (21d) with boundary conditions (22), the values of $y_{3}(0)=f^{\prime \prime}(0)$, $y_{5}(0)=f^{\prime \prime \prime \prime}(0)$ and $y_{7}(0)=\theta^{\prime}(0)$ are required but no such values are available in the boundary conditions. The suitable guess values for $f^{\prime \prime}(0), f^{\prime \prime \prime \prime}(0)$ and $\theta^{\prime}(0)$ are chosen and then numerical integration is performed. Thereafter the accuracy of the assumed missing initial condition is checked by comparing the calculated value of the dependent variable at the terminal point with its given value there. If a difference exists, the improved values of the missing initial conditions must be obtained and the process is repeated. Numerical solution of the problem is executed in the symbolic code, MATLAB. In order to validate the present solution of the problem and confirm accuracy, the shooting method solutions are compared with existing results from the literature for some special cases. A good agreement between the present and previous solution is achieved in Table 2 for the selected case of Ahmad et al. [62] $(A=0, \operatorname{Pr}=6.2, \lambda=0, \beta=0, E c=0, M=0)$, i.e. in the absence of stretching, zero convection parameter, Newtonian flow with no viscous or Ohmic dissipation. Furthermore, the present shooting method solutions are also compared in Table 3 with the earlier Newtonian results $(\beta=0)$ of Ishak et al. [61] when the buoyancy term $\lambda \theta$ in Eqn. (13) is absent and $A=0$ (steady-state flow) with $\operatorname{Pr}=1.0$. Again, excellent correlation is attained which confirms the validity of the shooting method computations. 
Table 2: Values of $-f^{\prime \prime}(0)$ for $M=0, \beta=0, K_{2}=0, B_{1}=0, E c=0, A=0, \lambda=0$

\begin{tabular}{|c|c|c|c|c|}
\hline $\boldsymbol{\varphi}$ & $\begin{array}{c}\text { Cu-water } \\
{[\mathbf{6 2}]}\end{array}$ & Present & $\begin{array}{c}\mathbf{A l}_{\mathbf{2}} \mathbf{O}_{3} \text {-water } \\
\text { [62] }\end{array}$ & Present \\
\hline 0.0 & 0.4446 & 0.4441 & 0.4446 & 0.4442 \\
\hline 0.002 & 0.4492 & 0.4489 & 0.4470 & 0.4468 \\
\hline 0.004 & 0.4538 & 0.4526 & 0.4494 & 0.4491 \\
\hline 0.008 & 0.4630 & 0.4624 & 0.4544 & 0.4540 \\
\hline 0.01 & 0.4676 & 0.4670 & 0.4568 & 0.4563 \\
\hline 0.012 & 0.4722 & 0.4716 & 0.4593 & 0.4589 \\
\hline 0.014 & 0.4768 & 0.4757 & 0.4618 & 0.4614 \\
\hline 0.016 & 0.4814 & 0.4809 & 0.4643 & 0.4639 \\
\hline 0.018 & 0.4860 & 0.4853 & 0.4668 & 0.4661 \\
\hline 0.02 & 0.4906 & 0.4901 & 0.4693 & 0.4688 \\
\hline 0.1 & 0.6788 & 0.6784 & 0.5778 & 0.5771 \\
\hline 0.2 & 0.9446 & 0.9439 & 0.7428 & 0.7422 \\
\hline
\end{tabular}

Table 3: Values of $-\theta^{\prime}(0)$ for $\beta=0, \varphi=0, M=0, E c=0$.

\begin{tabular}{|c|c|c|c|c|}
\hline $\mathbf{A}$ & $\boldsymbol{\lambda}$ & $\boldsymbol{P r}$ & Ishak et al. [61] & Present results \\
\hline 0 & 0 & 0.01 & 0.0197 & 0.2010 \\
\hline & & 0.72 & 0.8086 & 0.8158 \\
\hline & & 1.0 & 1.0000 & 1.0011 \\
\hline & & 3.0 & 1.9237 & 1.9230 \\
\hline & 1 & 1.0 & 1.0873 & 1.0868 \\
\hline & 2 & & 1.1423 & 1.1419 \\
\hline & 3 & & 1.1853 & 1.1850 \\
\hline 1 & 0 & & 1.6820 & 1.6910 \\
\hline & 1 & & 1.7039 & 1.7191 \\
\hline
\end{tabular}

\section{RESULTS AND DISCUSSION}

Flow and heat transfer characteristics for the couple stress magnetic nanofluid with two distinct nanoparticles, namely Copper $(\mathrm{Cu})$ and Aluminium Oxide $\left(\mathrm{Al}_{2} \mathrm{O}_{3}\right)$ suspended in a base fluid i.e., Newtonian $\left(\mathrm{H}_{2} \mathrm{O}\right.$-water), have been computed. All the results are visualized graphically in Figs. 211. for various values of emerging parameters, namely: couple stress parameter $(\beta)$, magnetic parameter $(M)$, Eckert number $(E c)$, convection parameter $(\lambda)$, stretching parameter $(A)$. The solid volume fraction of nanoparticles i.e. $\phi(=0.1)$ and Prandtl number of the base fluid i.e. $\operatorname{Pr} \quad(=6.2)$ 
are kept constant in Figs 2-11. Nano-particle volume fraction effect is explicitly studied in the skin friction and Nusselt number plots (Fig. 12). The thermophysical properties of water and nanoparticles $\mathrm{Cu}$ and $\mathrm{Al}_{2} \mathrm{O}_{3}$ are shown in Table 1.

Figures 2-6 illustrate the evolution in velocity profile, $f^{\prime}(\eta)$ for Copper $(\mathrm{Cu})$ and Aluminium Oxide $\left(\mathrm{Al}_{2} \mathrm{O}_{3}\right)$ nano-particles for various values of physical parameters. Figs. 2(a)-(b) indicate that the velocity is markedly modified by the couple stress rheological parameter $\beta$ for both cases. From theses graph it is seen that nearby the sheet, the velocity upsurges for increasing in $\beta$ values. This is due to the reduction in contribution of couple stresses in the nano-polymer which generally accelerates the flow closer to the wall in the boundary layer transverse to the sheet. However further from the wall this trend is reversed. For couple-stress fluids, the shear stress tensor is not symmetric (unlike with Newtonian fluids where it is symmetric). The body couples in the fluid now contribute to encouraging motion which leads to a thinning of the momentum boundary layer. As $\beta \rightarrow \infty$, the properties of couple-stress in the fluid vanish and the nano-polymer assumes Newtonian behaviour. Weaker couple stress effect is therefore less inhibitive to the boundary layer. This has been demonstrated in numerous studies including Cowin [63] and Tripathi et al. [64]. It is further of note that higher velocities are attained for the Aluminium oxide nano-particle case (Fig. 2b) compared with the copper nano-particle case (Fig. 2a)

Figs. 3(a)-(b) depict the influence of magnetic parameter, $M$, on velocity distributions. With increasing $M$ the flow is accelerated throughout the boundary layer transverse to the sheet. This is the contrary response to conventional magnetohydrodynamic boundary layers. The stretching of the sheet results in the magnetic field being dragged in the free stream direction which effectively decelerates rather than accelerates the flow. The momentum boundary layer is therefore reduced in thickness with greater magnetic field parameter, as noted by Zueco et al. [49]. The enhancement in velocity is noticeably greater for the case of copper nano-particles compared with Aluminium oxide nano-particles. Evidently magnetic field induces significant alteration in the shear characteristics of magnetic nano-polymers leading to acceleration in the boundary layer flow for both types of nanoparticles.

Figs. 4(a)-(b) portray the impact of unsteadiness parameter, $A$, on velocity through the boundary layer. The parameter $A$, describe the unsteadiness in the stretching sheet flow. Inspection of Fig. 3(a) reveals that velocity exhibit a decreasing trend with amplified values of $A$. This is owing to fact that $A$ is inversely proportional to the stretching coefficient $a$. Thus, elevation in values of $A$ decreases the stretching ratio. As a consequence of this the momentum boundary layer thickness is increased. 
However reverse flow is never induced in the boundary layer as testified to by consistently positive values of the velocity for any value of the unsteadiness parameter, $A$. Similar observations have been made by Wang et al. [34] for Newtonian fluids and Ferdows et al. [56] for magnetic nanofluids.

Figs. 5(a)-(b) respectively depicts the variation of convection parameter $\lambda$ on velocity curves. The influence of increasing values of $\lambda$ is to escalate the velocity and therefore to deplete the momentum boundary layer thickness in the magnetic nanofluid. Physically $\lambda>0$ signifies assisting flow (heating of the fluid), $\lambda<0$ reveals opposing flow (cooling of the fluid) and $\lambda=0$ implies forced convection flow (absence of free convection currents). Also, it is noted that initially assisting flow $(\lambda=-0.1)$ dominates the opposing flow. Irrespective of the values of $\lambda$, the curves are consistently monotonic decays from the wall to the free stream.

Finally, the Figs. 6(a)-(b) illustrate the impact of $E c$ on flow-field velocity profiles. An augmenting value of $E c$ the velocity increases. Although conventionally viscous heating results in flow deceleration and conversion of mechanical energy to heat, the convection parameter $(\lambda)$ reverses this process. Profiles of velocity are also morphed from strongly parabolic decays to a more linear distribution. Copper nano-particles are associated with significantly lower velocities (thicker momentum boundary layer) whereas the Aluminium oxide nano-particles produce higher velocities (thinner momentum boundary layer) irrespective of the value of the Eckert number.

Figures 7-11 signifies temperature profiles $\theta(\eta)$ of $\mathrm{Cu}$ and $\mathrm{Al}_{2} \mathrm{O}_{3}$ for various values of nondimensional parameters. Figs. 7(a)-(b) describes the variation of temperature profiles for different values of the couple stress parameter, $\beta$. It is evident that a rise in $\beta$ values corresponds to an increase in temperature. In other words, as the magnetic nanofluid behaviour approaches Newtonian behaviour, temperatures are greater and thermal boundary layer thickness is enhanced. The couple stress effect does not arise in the thermal boundary layer Eqn. (14). However, via coupling with the momentum Eqn. (13) through the buoyancy term, $\lambda \theta$, and the convective terms in the energy Eqn. (14) i.e. $+f \theta^{\prime}-\theta f^{\prime}$, a strong effect is induced in the thermal field. Also, it is noticed that behaviour of the $\mathrm{Al}_{2} \mathrm{O}_{3}$ temperature profile is most pronounced at some distance from the sheet i.e. towards the free stream as compared to temperature magnitudes computed for the copper nano-particle case.

Figs. 8(a)-(b) denotes the influence of parameter $M$ on temperature graphs. It is seen that as $M$ increases there is considerable elevation in magnitudes of the temperature profiles for both the nanoparticles $\left(\mathrm{Cu}\right.$ and $\left.\mathrm{Al}_{2} \mathrm{O}_{3}\right)$ upsurges. Additional work has to be performed to drag the magnetic nanofluid against the action of the transverse magnetic field. This supplementary work is dissipated 
as thermal energy and this heats the boundary layer. Furthermore, there is the additional effect of Ohmic dissipation as simulated via the term, $\frac{1}{K_{3}} B_{1} M E c f^{\prime 2}$ in the energy conservation Eqn. (14). This further amplifies the quantity of kinetic energy dissipated as thermal energy in the regime. Thermal boundary layer thickness is therefore substantially increased with stronger magnetic field i.e. greater values of magnetic parameter. The topology of profiles is also significantly different for the copper and aluminium oxide nano-particle cases. Very steep descents from the wall to the free stream are computed for the copper case, with a temperature shoot arising in close proximity to the wall only when magnetic parameter exceeds unity $(M>1.0)$. However, in the aluminium oxide case, inverted parabolas are generated for $M>1$ and a more consistent temperature distribution is attained across the boundary layer transverse to the wall. Furthermore, significantly higher peak temperature is computed for the aluminium oxide nano-particle case. Evidently the magnetic field is a critical parameter contributing to control of temperatures in the magnetic nanofluid.

Figs. 9(a)-(b) portray the impact of sheet stretching parameter, $A$ on temperature evolution through the boundary layer. Significantly higher thermal boundary layer thickness is computed for aluminium oxide relative to copper nanoparticles over the same increment in values of $A$. Temperature profiles for copper nanoparticles follow a similar trend to that of velocity. Increasing stretching parameter $A$ generally depletes temperature. Since the fluid flow is initiated by stretching of the sheet, hence temperature reduces with enlarging $\eta$ and thermal boundary thickness decreases with augmenting $A$ values. However, $\mathrm{Al}_{2} \mathrm{O}_{3}$ temperature profile decreases with greater values of $A$ as shown in Fig. 9(b).

Figs. 10(a)-(b) present the impact of convective parameter, $\lambda$ on temperature profiles. As $\lambda$ augments this generates a decrease in the temperatures. This leads to reduction in the thermal boundary layer thickness. A more even distribution of temperature is achieved across the boundary layer for the aluminium oxide case and furthermore much higher temperatures are produced. For the buoyancy-opposing case $(\lambda<0)$ the maximum temperatures are computed for both nano-particles. For the buoyancy-assisted flow scenario $(\lambda>0)$, the minimum temperatures are observed. The case of $\lambda=0$ i.e. pure forced convection flow falls between the other two scenarios.

Figs. 11(a)-(b) describe the influence of Ec on temperature profiles. $\theta(\eta)$ profiles show increasing trend for augmenting values of Ec. With increasing Eckert number, there is greater conversion of kinetic energy to thermal energy. This results in heating of the magnetic nanofluid and a thickening in thermal boundary layer thickness. The results indicate that neglection of viscous dissipation in magnetic nano-materials processing results in under-prediction of actual temperatures which in turn 
will lead to erroneous results for heat transfer rates at the wall. Again notably higher temperatures are computed for the Aluminium oxide nano-particle case compared with the copper case.

Figs. 12(a)-(b) present respectively the distributions for skin friction and Nusselt number with nanoparticle volume fraction $(\phi)$ for both copper and aluminium oxide nano-particles. A distinct elevation in both skin friction and Nusselt number accompany an increase in nano-particle volume fraction. Increased doping of the water-based polymer with metallic nano-particles therefore induces both flow acceleration and enhanced removal of heat from the fluid to the wall. These are both desirable in materials processing operations. Significantly the copper nano-particle case produces higher Nusselt numbers for any magnitude of volume fraction and this is associated with the enhanced thermal conductivity of copper which removes heat faster from the boundary layer to the wall.

\section{CONCLUSIONS}

A theoretical study of a mathematical model unsteady rheological magnetic nano-polymer boundary layer flow and heat transfer over a vertical stretching sheet in the presence of a transverse static magnetic field with buoyancy, Joule heating (Ohmic dissipation) and viscous heating effects is presented. Stokes' couple stress model has been employed to simulate non-Newtonian microstructural characteristics. The Tiwari-Das nanoscale model has been utilized to analyse different nano-particles (copper-water and aluminium oxide-water nanofluids). The normalized momentum and energy boundary layer equations are solved subject to appropriate wall and free stream boundary conditions with a shooting technique in MATLAB symbolic software. Validation of the shooting solutions with published results from the literature is included. The computations show that:

(i) Fluid velocity and temperature profiles for both Copper and Aluminium Oxide $\left(\mathrm{Al}_{2} \mathrm{O}_{3}\right)$ nanofluids are enhanced with greater non-Newtonian couple stress parameter and magnetic parameter whereas the opposite trend is computed with greater values of unsteadiness parameter.

(ii) Temperatures are also boosted with magnetic parameter and exhibit an overshoot near the wall when magnetic parameter exceeds unity (magnetic force exceeds viscous force).

(iii) Velocities are elevated with increasing buoyancy parameter, elastic sheet stretching parameter and convection parameter and momentum boundary layer thickness is reduced.

(iv) Temperatures are generally increased with greater couple stress rheological parameter and are consistently higher for the Aluminium oxide nano-particle case.

(v) Temperatures (and thermal boundary layer thickness) are depleted with increasing sheet stretching parameter whereas they are markedly elevated with increasing Eckert number.

(vi) With increasing nano-particle volume fraction both skin friction and Nusselt number are elevated and copper nano-particles achieve higher magnitudes than aluminium oxide. 
The present work has shown that simulations of magnetic nano-polymer processing are improved with inclusion of dissipative (viscous and Ohmic) effects. Future studies will examine alternate nanoscale models e.g. Buongiorno's model and will also consider Brownian diffusion and thermophoresis effects in nano-polymer processing.

\section{Acknowledgements:}

The first author wishes to thank DST-INSPIRE (Code No. IF160028) for the grant of research fellowship and to Central University of Karnataka for providing the research facilities. The authors wish to express their gratitude to the reviewers who highlighted important areas for improvement in this article. Their suggestions have served to enhance the clarity and depth of the interpretation in particular.

\section{$\underline{\text { Figure caption list }}$}

Figure 1 Magnetic nano-polymer stretching stretching sheet configuration.

Figure 2a, b Simulated velocity profiles for various values of couple stress parameter when $E c=1.0, M=1.0, A=0.2, \lambda=1.0$.

Figure 3a, b Simulated velocity profiles for various values of magnetic parameter when $E c=$ $1.0, \beta=1.0, A=0.2, \lambda=1.0$.

Figure 4a, b Simulated velocity profiles for various values of stretching parameter when $E c=$ $1.0, \beta=1.0, M=1.0, \lambda=1.0$.

Figure 5a, b Simulated velocity profiles for various values of convection parameter when $E c=1.0, \beta=1.0, M=1.0, A=0.2$.

Figure 6a, $\mathbf{b} \quad$ Simulated velocity profiles for various values of Eckert number when $\lambda=1.0, \beta=1.0, M=1.0, A=0.2$.

Figure 7a, $\mathbf{b}$ Simulated temperature profiles for various values of couple stress parameter when $E c=1.0, M=1.0, A=0.2, \lambda=1.0$.

Figure 8a, $\mathbf{b}$ Simulated temperature profiles for various values of magnetic parameter when $E c=1.0, \beta=1.0, A=0.2, \lambda=1.0$.

Figure 9a, b Simulated temperature profiles for various values of stretching parameter when $E c=1.0, \beta=1.0, M=1.0, \lambda=1.0$.

Figure 10a, b Simulated temperature profiles for various values of convection parameter when $E c=1.0, \beta=1.0, M=1.0, A=0.2$. 
Figure 11a, $\mathbf{b}$ Simulated temperature profiles for various values of Eckert number when $\lambda=1.0, \beta=1.0, M=1.0, A=0.2$.

Figure 12a, b Simulated skin friction coefficient and Nusselt number profiles versus volume fraction $(\phi)$ for different nano-particles when $\lambda=0.1, \beta=1.0, M=1.0, A=$ $0.2, E c=1.0$.

\section{Table caption list}

Table 1 Thermophysical properties of base fluids and nanoparticles.

Table 2 Values of $-f^{\prime \prime}(0)$ for $M=0, \beta=0, K_{2}=0, B_{1}=0, E c=0, A=0, \lambda=0$.

Table 3 Values of $-\theta^{\prime}(0)$ for $\beta=0, \varphi=0, M=0, E c=0$.

\section{Notations}

a stretching rate based on surface velocity $(1 / s)$

A unsteadiness parameter (-)

$\mathrm{Al}_{2} \mathrm{O}_{3} \quad$ Aluminium Oxide

$b \quad$ stretching rate based on surface temperature $(1 / s)$

$B_{0} \quad$ applied magnetic field $\left(\mathrm{Kg}^{2} \mathrm{~s}^{-4} \mathrm{~A}^{-2}\right)$

c dimensional constant $(1 / s)$

$C_{f} \quad$ local skin-friction (-)

$C_{p} \quad$ specific heat at constant pressure $(\mathrm{J} / \mathrm{kg} \mathrm{K})$

$\mathrm{Cu} \quad$ Copper

Ec $\quad$ Eckert number $(-)$

$f^{\prime}(\eta) \quad$ dimensionless stretching sheet velocity $(-)$

$g \quad$ acceleration due to gravity $\left(\mathrm{m} / \mathrm{s}^{2}\right)$

Gr local Grashof number (-)

$k \quad$ thermal conductivity $(\mathrm{W} / \mathrm{mK})$

$m \quad$ nanoparticle shape factor 


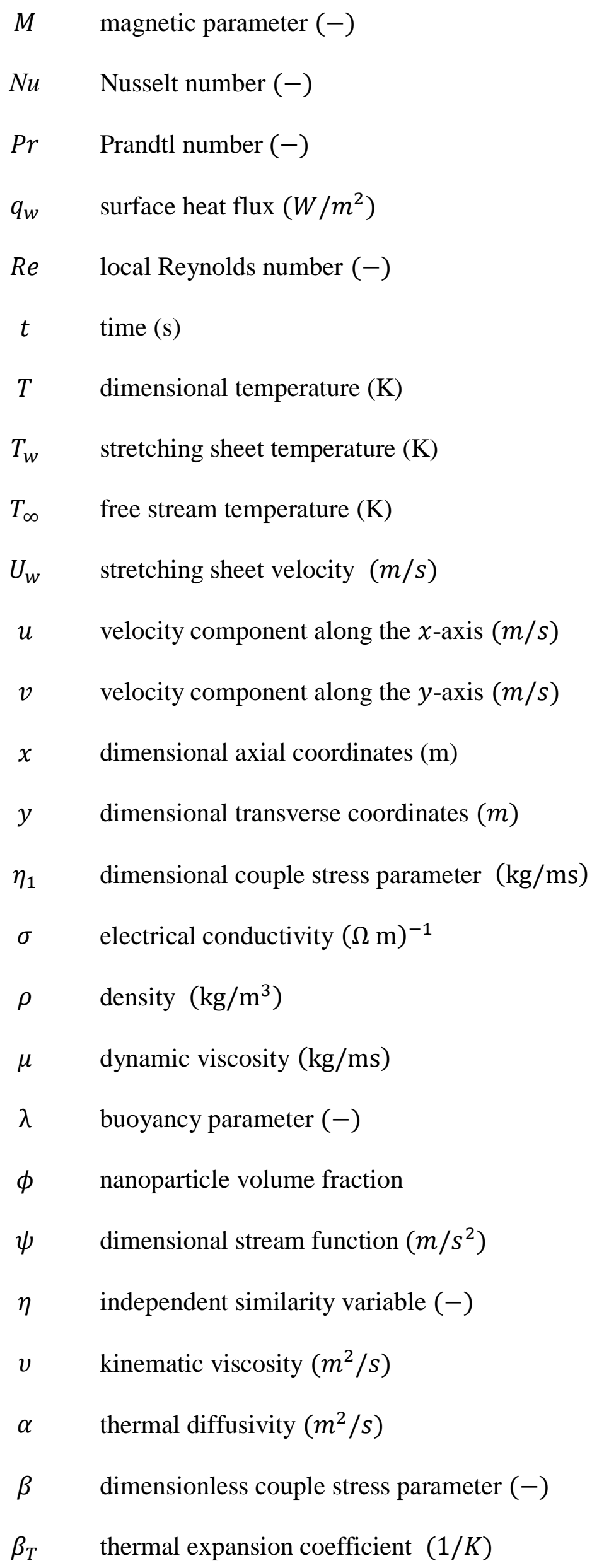


$\theta(\eta) \quad$ dimensionless stretching temperature $(-)$

$\tau_{\mathrm{w}} \quad$ shear stress $\left(N / m^{2}\right)$

\section{Subscript}

()$_{w} \quad$ condition at wall

()$_{\infty} \quad$ condition at ambient

( ) $n f \quad$ effective nanofluid

()$_{f} \quad$ nanoparticles

()$_{s} \quad$ basefluid

\section{REFERENCES}

1. Choi SUS and Eastman JA. Enhancing thermal conductivity of fluids with nanoparticles In: Siginer DA and Wang H-P (eds) Developments and applications of non-Newtonian flows, Vol. 231. New York: American Society of Mechanical Engineers, 1995, pp.99-106.

2. Lee S and Choi SUS. Application of metallic Nanoparticle suspensions in advanced cooling systems. In 1996 International Mechanical Engineering Congress and Exhibition. Atlanta, USA (1996).

3. Teng TP, Hung YH, Teng TC, et al. The effect of alumina/water nanofluid particle size on thermal conductivity. Applied Thermal Engineering 2010; 30; 2213-2218.

4. Tabasum R, Mehmood R and Pourmehran O. Velocity slip in mixed convective oblique transport of titanium oxide/water (nano-polymer) with temperature-dependent viscosity. European Physical Journal Plus 2018; 133; 1-12.

5. Timofeeva EV, Smith DS, Yu W, et al. Particle size and interfacial effects on thermo-physical and heat transfer characteristics of water-based a-SiC nanofluids. Nanotechnology 2010; 21; $1-10$.

6. Lee DW and Kim BK. Nanostructured $\mathrm{Cu}-\mathrm{Al}_{2} \mathrm{O}_{3}$ composite produced by thermochemical process for electrode application. Materials Letters 2004; 58; 378-383.

7. Nasiri $\mathrm{H}$, Vahdati $\mathrm{KJ}$ and Zebarjad $\mathrm{SM}$. One-step fabrication of $\mathrm{Cu}-\mathrm{Al}_{2} \mathrm{O}_{3}$ nanocomposite via solution combustion synthesis route. Journal of Alloys and Compounds 2011; 509; 53055308 .

8. Shehata F, Abdelhameed M, Fathy A, et al. Preparation and characteristics of $\mathrm{Cu}-\mathrm{Al}_{2} \mathrm{O}_{3}$ nanocomposite, Open Journal of Metal 2011; 1; 25-33. 
9. Park SJ, Yoo K, Kim, JY, et al. Water-based thixotropic polymer gel electrolyte for dyesensitized solar cells. American Chemical Society 2013; 7; 4050-4056.

10. Guari Y, Larionova J, Molvinger K, et al. Magnetic water-soluble cyano-bridged metal coordination nano-polymers. Chem. Commun 2006; 24; 2613-2615.

11. Moghadam PN, Hasanzadeh R, Fathi F, et al. Comparative study for adsorption of Al (III) ions from aqueous solutions with series of nano functional copolymers. J. Macromolecular Science, Part A 2013; 50; 1167-1181.

12. Nurikiyimfura I, Wang Y and Pan Z. Heat transfer enhancement by magnetic nanofluids. Renewable and Sustainable Energy Reviews 2013; 21; 548-561.

13. Nurikiyimfura I, Wang Y and Pan Z. Effect of chain-like magnetite nanoparticle aggregates on thermal conductivity of magnetic nanofluid in magnetic field. Experimental Thermal and Fluid Science 2013; 44; 607-612.

14. Rana $\mathrm{O}$ and Bég OA. Mixed convection flow along an inclined permeable plate: effect of magnetic field, nanolayer conductivity and nanoparticle diameter. Applied Nanoscience 2014; 5; 569-581.

15. Sandeep N. Effect of aligned magnetic field on liquid thin film flow of magnetic-nanofluids embedded with graphene nanoparticles. Adv Powder Technol 2017; 28; 865-875.

16. Muthukumaran T, Gnanaprakash G and Philip J. Synthesis of stable magnetic nanofluids of different particle sizes. J Nanofluids 2012; 1; 85-92.

17. Uddin MJ, Bég OA and Amin N. Hydromagnetic transport phenomena from a stretching or shrinking nonlinear nanomaterial sheet with Navier slip and convective heating: a model for bio nanomaterials processing. J Mag Magn Mater 2014; 368; 252-261.

18. Dekker CV. Magnetic Nanoparticles: Preparation and Properties. Encyclopedia of Nanoscience and Nanotechnology, New York; USA; Roldan Group Publications; 2004; Chapter 119.

19. Bao Y, Pakhomov AB and Krishnan KM, Brownian magnetic relaxation of water-based cobalt nanoparticle ferrofluids. J Appl Phys 2006; 99; 1-3.

20. William JKM, Ponmani S, Samuel R, et al. Effect of $\mathrm{CuO}$ and $\mathrm{ZnO}$ nanofluids in xanthan gum on thermal, electrical and high pressure rheology of water-based drilling fluids. J Petrol Sci and Eng 2014; 117; 15-27.

21. Katiyar A, Singh AN, Shukla P, et al. Rheological behavior of magnetic nanofluids containing spherical nanoparticles of Fe-Ni. Powder Technol 2012; 224; 86-89.

22. Sharma AK, Tiwari AK and Dixit AR. Rheological behaviour of nanofluids: A review. Renewable and Sustainable Energy Reviews 2016; 53; 779-791.

23. Hojjat M, Etemad SG, Bagheri R, et al. Rheological characteristics of non-Newtonian nanofluids: Experimental investigation. Int J Heat Mass Tran 2011; 38; 144-148. 
24. Yang JC, Li FC, Zhou WW, et al. Experimental investigation on the thermal conductivity and shear viscosity of viscoelastic-fluid-based nanofluids. Int J Heat Mass Transf 2012; 55; 31603166.

25. Bég OA, Espinoza DES, Kadir A, et al. Experimental study of improved rheology and lubricity of drilling fluids enhanced with nano-particles. Appl Nanosci 2018; 8; 1069-1090.

26. Beg OA, Kuharat S, Mehmood R, et al. Oblique radiative solar nano-polymer gel coating heat transfer and slip flow: manufacturing simulation. ICHTFM 2018: $20^{\text {th }}$ International Conference on Heat Transfer and Fluid Mechanics 2018, Istanbul, Turkey.

27. Sakiadis BC. Boundary layer behavior on continuous solid surfaces: I boundary layer equations for two dimensional and axisymmetric flow. AIChE J 1961; 7; 26-28.

28. Rajagopal KR, Na TY and Gupta AS. Flow of a visco-elastic fluid over a stretching sheet. Rheol Acta 1984; 23; 213-215.

29. Khan M and Shehzad A. On boundary layer flow of a Sisko fluid over a stretching sheet. Quaes Mathe 2013; 36; 137-145.

30. Mahmoud MAA and Megahed AM. Non-uniform heat generation effect on heat transfer of a non-Newtonian power-law fluid over a non-linearly stretching sheet. Meccanica 2012; 47; 1131-1140.

31. Bachok N, Ishak A and Pop I. Boundary layer stagnation-point flow and heat transfer over an exponentially stretching/shrinking sheet in a nanofluid. Int J Heat and Mass Trans 2012; 55; 8122-8128.

32. Hayat T, Imtiaza M, Alsaedi A. MHD flow of nanofluids over an exponentially stretching sheet in a porous medium with convective boundary conditions. Chin Phys B 2014; 23; 054701.

33. Anjali DSP and Suriya DUS. Numerical investigation of hydromagnetic hybrid $\mathrm{Cu}$ $\mathrm{Al}_{2} \mathrm{O}_{3} /$ Water nanofluid flow over a permeable stretching sheet with suction. Int $J$ Non-linear Sci Num Simul, 2016; 17; 249-257.

34. Wang CY, Du G, Miklavi M, et al. Impulsive stretching of a surface in a viscous fluid. SIAM J Appl Math 1997; 57; 1-14.

35. Tarakaramu N and Narayan PVS. Unsteady MHD nanofluid flow over a stretching sheet with chemical reaction. Mater Sci Eng 2017; 263; 1-9.

36. Hussanan A, Salleh MZ and Khan I. Microstructure and inertial characteristics of a magnetite ferrofluid over a stretching/shrinking sheet using effective thermal conductivity model. $J \mathrm{Mol}$ Liq 2018; 255; 64-75.

37. Stokes VK. Couple stresses in fluids. Phy Fluids 1966; 9; 1709-1715.

38. Khan NA, Riaz F and Khan NA. Heat transfer analysis for couple stress fluid over a nonlinearly stretching sheet. Nonlin Eng 2013; 2, 121-127. 
39. Ramana Murthy JV, Srinivas J and Bég OA. Entropy generation analysis of radiative heat transfer effects on channel flow of two immiscible couple stress fluids. J Brazilian Soc Mech Sci Eng 2017; 39; 2191-2202.

40. Hayat T, Awais M, Ambreen SA, et al. Unsteady three-dimensional flow of couple stress fluid over a stretching surface with chemical reaction. Nonlin Anal: Mod Cont 2012; 17; 4759.

41. Tripathi D, Yadav A and Bég OA. Electro-osmotic flow of couple stress fluids in a microchannel propagated by peristalsis. European Phy J Plus 2017; 132; 173-185.

42. Awais M, Saleem S, Hayat T, et al. Hydromagnetic couple-stress nanofluid flow over a moving convective wall: OHAM analysis. Acta Astronautica 2016; 129; 271-276.

43. Makinde OD and Eegunjobi AS. MHD couple stress nanofluid flow in a permeable wall channel with entropy generation and nonlinear radiative heat. ASME J Thermal Sci Tech $2017 ; 12 ; 1-17$.

44. Awad F, Haroun NAH, Sibanda P, et al. On couple stress effects on unsteady nanofluid flow over stretching surfaces with vanishing nanoparticle flux at the wall. J Appl Fluid Mech 2016; 9; $1937-1944$.

45. Chand R, Yadav D and Rana RC, et al. Thermal instability of couple-stress nanofluid with vertical rotation in a porous medium. J Porous Media, 2016; 20; 635-648.

46. Rehman A, Nadeem S and Malik MY. Stagnation flow of couple stress nanofluid over an exponentially stretching sheet through a porous medium. J Power Technol 2013; 93; 122 132.

47. Shamshuddin MD, Mishra SR, Bég OA et al. Unsteady reactive magnetic radiative micropolar flow, heat and mass transfer from an inclined plate with Joule heating: a model for magnetic polymer processing. Proc IMechE Part C: J Mechanical Engineering Science 2018; $1-16$.

48. Sahoo B. Effects of partial slip, viscous dissipation and Joule heating on von Karman flow and heat transfer of an electrically conducting non-Newtonian fluid. Commun Nonlinear Sci Num Simul 2009; 14; 2982-2998.

49. Zueco J, Bég OA, Takhar HS, et al. Thermophoretic hydromagnetic dissipative heat and mass transfer with lateral mass flux, heat source, Ohmic heating and thermal conductivity effects: network simulation numerical study. Appl Ther Eng 2009; 29; 2808-2815.

50. Tripathi D, Ashish S and Bég OA. Electrothermal transport of nanofluids via peristaltic pumping in a finite micro-channel: effects of Joule heating and Helmholtz-Smoluchowski velocity. Int J Heat Mass Trans 2017; 111; 138-149.

51. Ghadikolaei SS, Hosseinzadeh K, Ganji DD, et al. Nonlinear thermal radiation effect on magneto Casson nanofluid flow with Joule heating effect over an inclined porous stretching sheet. Case Studies in Therm Eng 2018; 12; 176-187. 
52. Hussain A, Malik MY, Salahuddin T, et al. Combined effects of viscous dissipation and Joule heating on MHD Sisko nanofluid over a stretching cylinder. J Mol Liq, 2017; 231; 341-352.

53. Shagaiya DY, Abdul AZ, Ismail Z, et al. Effects of thermal radiation, viscous and Joule heating on electrical MHD nanofluid with double stratification. Chin J Phy 2017; 55; 630651.

54. Nandkeolyar R, Motsa SS and Sibanda, P. Viscous and Joule heating in the stagnation point nanofluid flow through a stretching sheet with homogenous-heterogeneous reactions and nonlinear convection. ASME J Nanotechnol Eng Med 2014; 4; 1-10.

55. Tiwari RK and Das MK. Heat transfer augmentation in a two-sided lid-driven differentially heated square cavity utilizing nanofluids. Int J Heat Mass Trans 2007; 50; 2002-2018.

56. Ferdows M, Khan MS, Bég OA, et al. Numerical study of transient magnetohydrodynamic radiative free convection nanofluid flow from a stretching permeable surface. Proc. IMechEPart E: J Proc Mech Eng 2014; 228; 181-196.

57. Meade DB, Haran BS and White RE. The shooting technique for the solution of two-point boundary value problems. Maple Technol 1996; 3; 85-93.

58. Han X, Meng X and Li C. Buoyancy-driven convection heat transfer of copper-water nanofluid in a square enclosure under the different periodic oscillating boundary temperature waves. Case Stud Ther Eng 2015; 6; 93-103.

59. Saranya S, Ragupathi P, Ganga B, et al. Non-linear radiation effects on magnetic/nonmagnetic nanoparticles with different base fluids over a flat plate. Adv Powder Technol 2018; 29; 1977-1990.

60. Motlagh SY and Soltanipour $\mathrm{H}$. Natural convection of $\mathrm{Al}_{2} \mathrm{O}_{3}$-water nanofluid in an inclined cavity using Buongiorno's two-phase model. Int J Ther Scie, 2017; 111; 310-320.

61. Ishak, Nazar R and Pop I. Boundary layer flow and heat transfer over an unsteady stretching vertical surface. Meccanica 2009; 44; 369-375.

62. Ahmad S, Rohni AM and Pop I. Blasius and Sakiadis problems in nanofluids. Acta Mech $2011 ; 218 ; 195-204$.

63. Cowin SC. The theory of polar fluids. Adv Appl Mech 1974; 14; 279-347.

64. Tripathi D, Jhorar R, Bég OA et al. Electro-magneto-hydrodynamic peristaltic pumping of couple stress biofluids through a complex wavy micro-channel. J Mol Liq 2017; 236; 358367. 


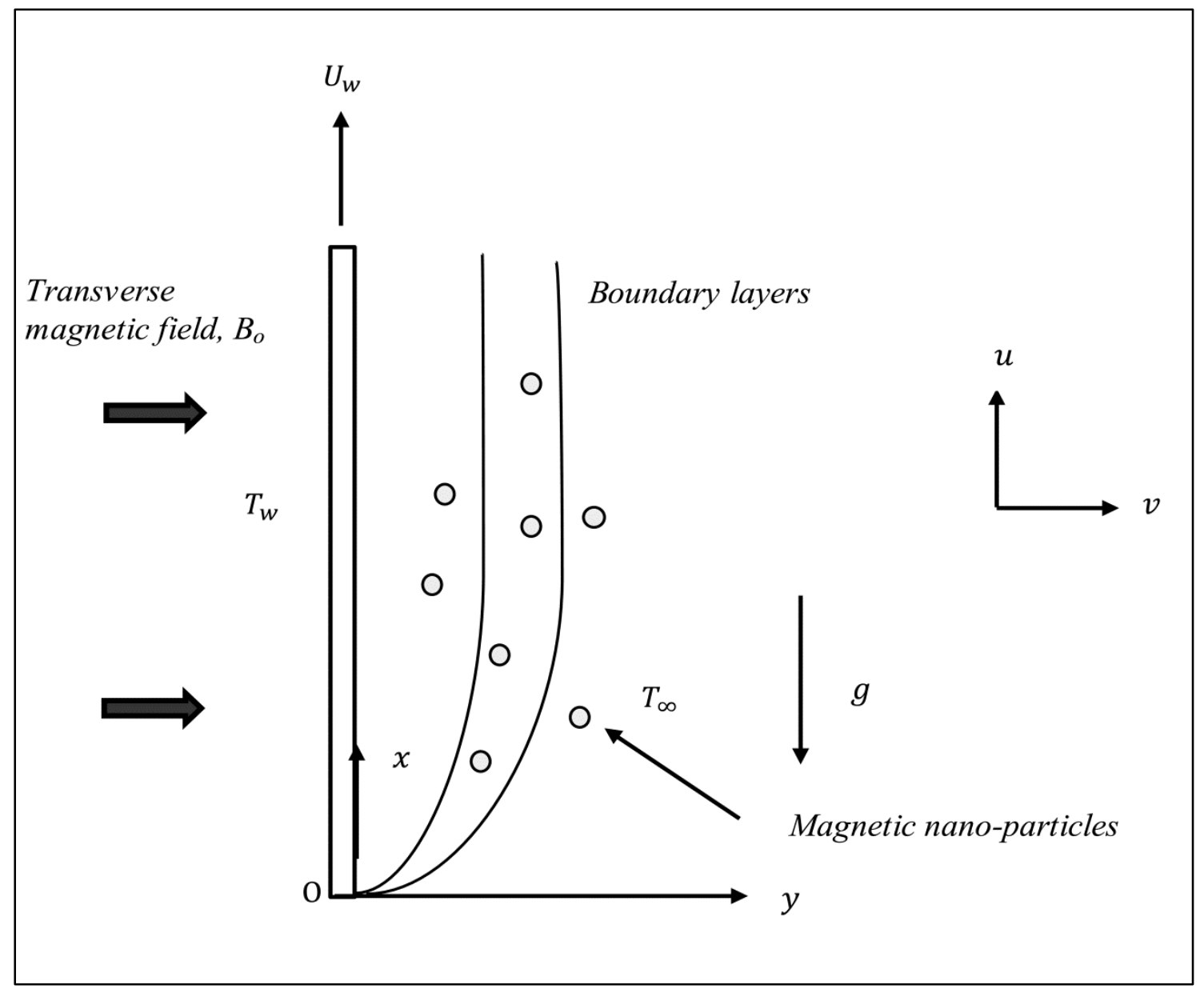

Figure 1. Magnetic nano-polymer stretching stretching sheet configuration. 


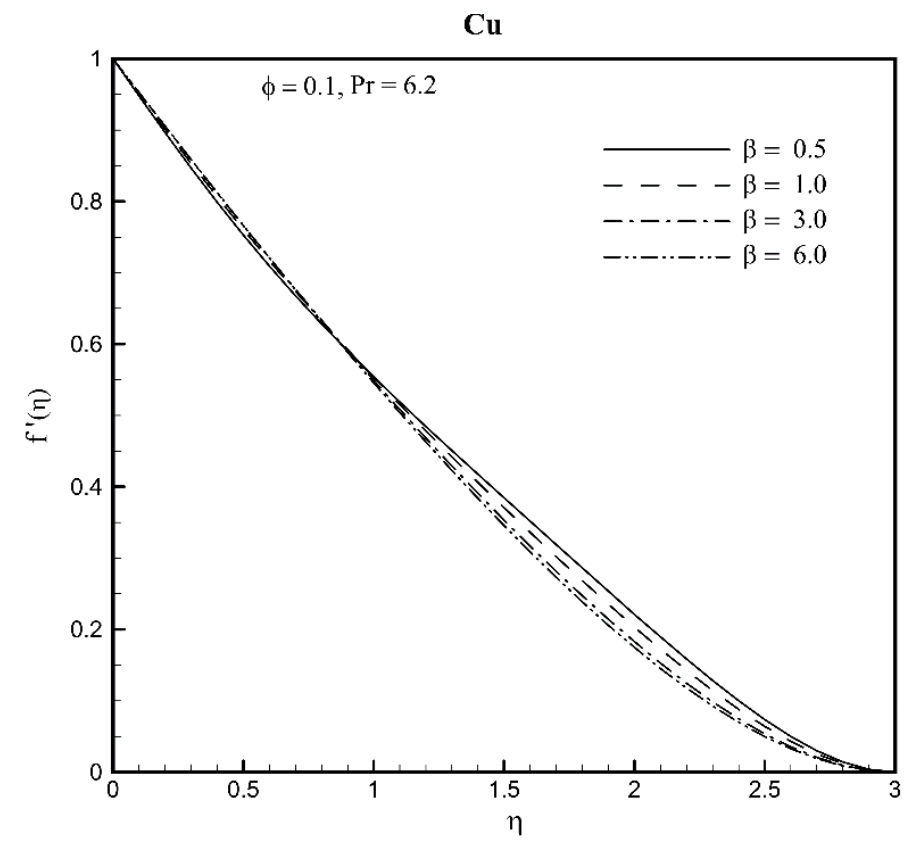

(a)

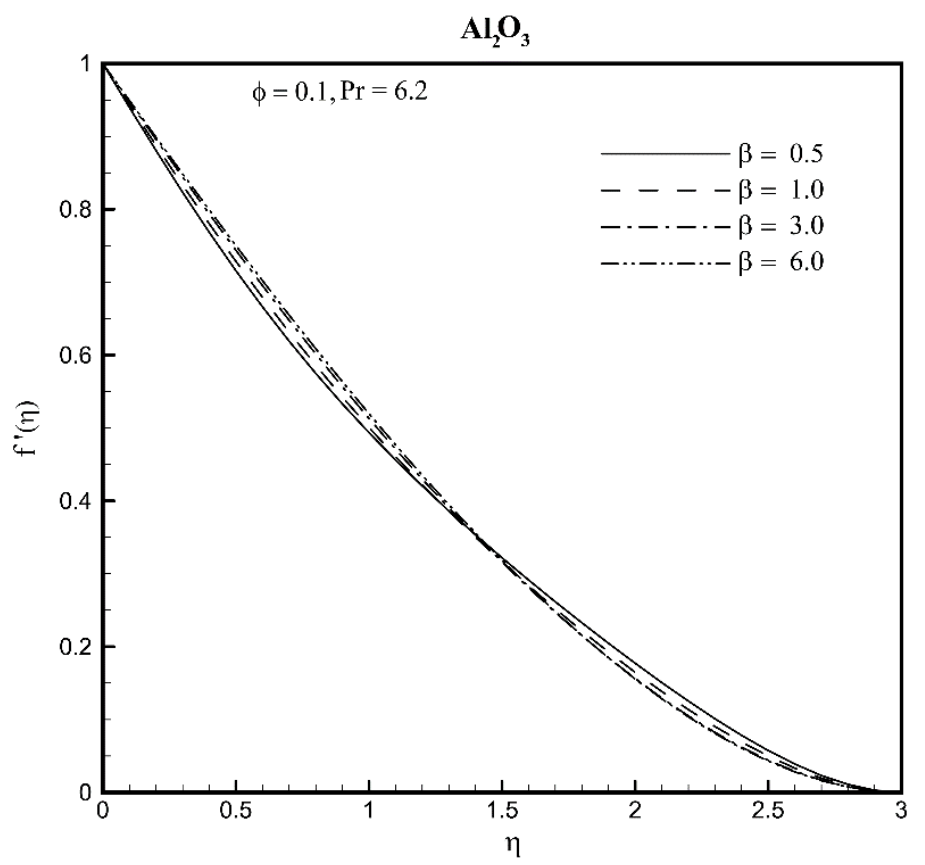

(b)

Figure 2a, b. Simulated velocity profiles for various values of couple stress parameter when $E c=$ $1.0, M=1.0, A=0.2, \lambda=1.0$.

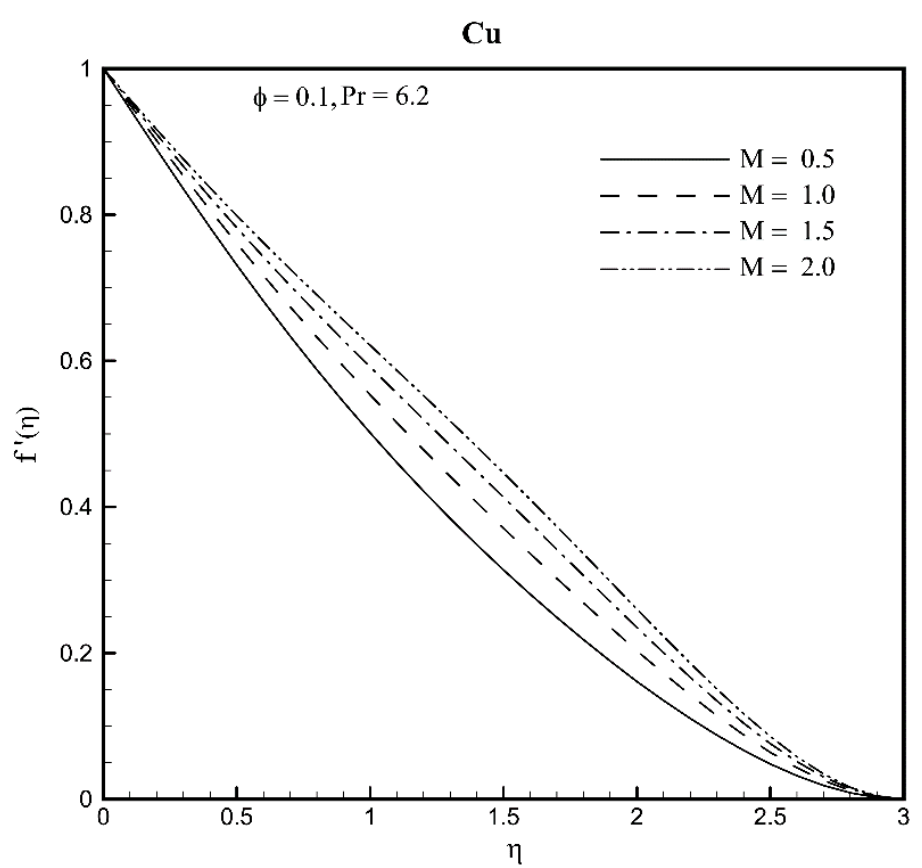

(a)

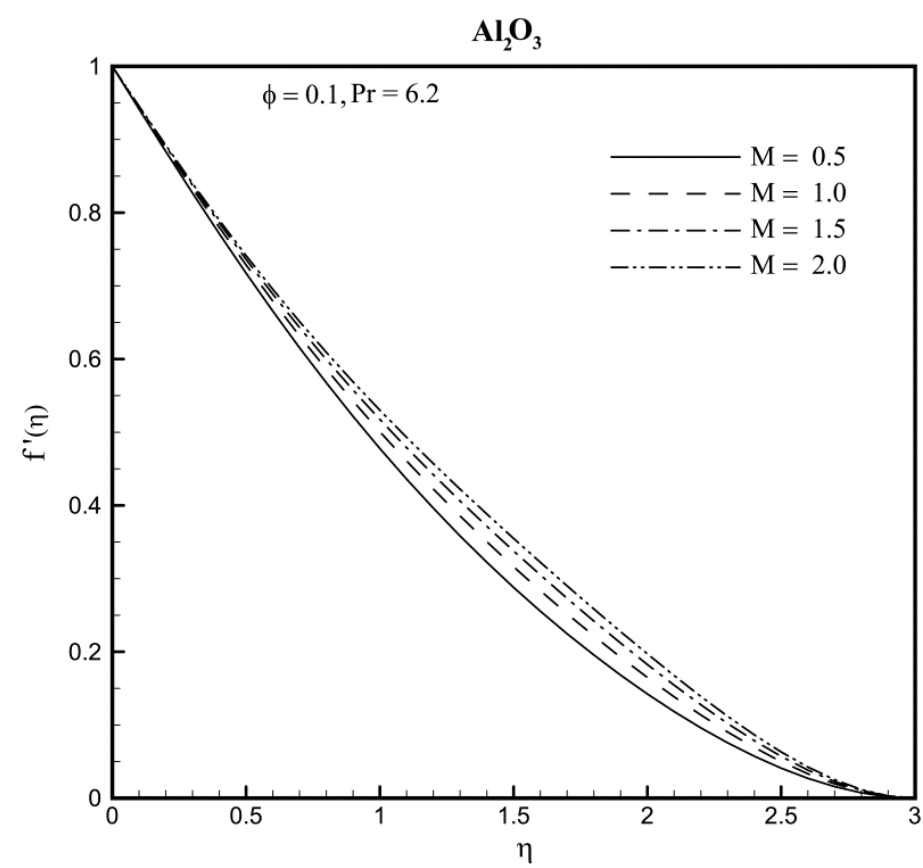

(b)

Figure 3a, b. Simulated velocity profiles for various values of magnetic parameter when $E c=$ $1.0, \beta=1.0, A=0.2, \lambda=1.0$. 


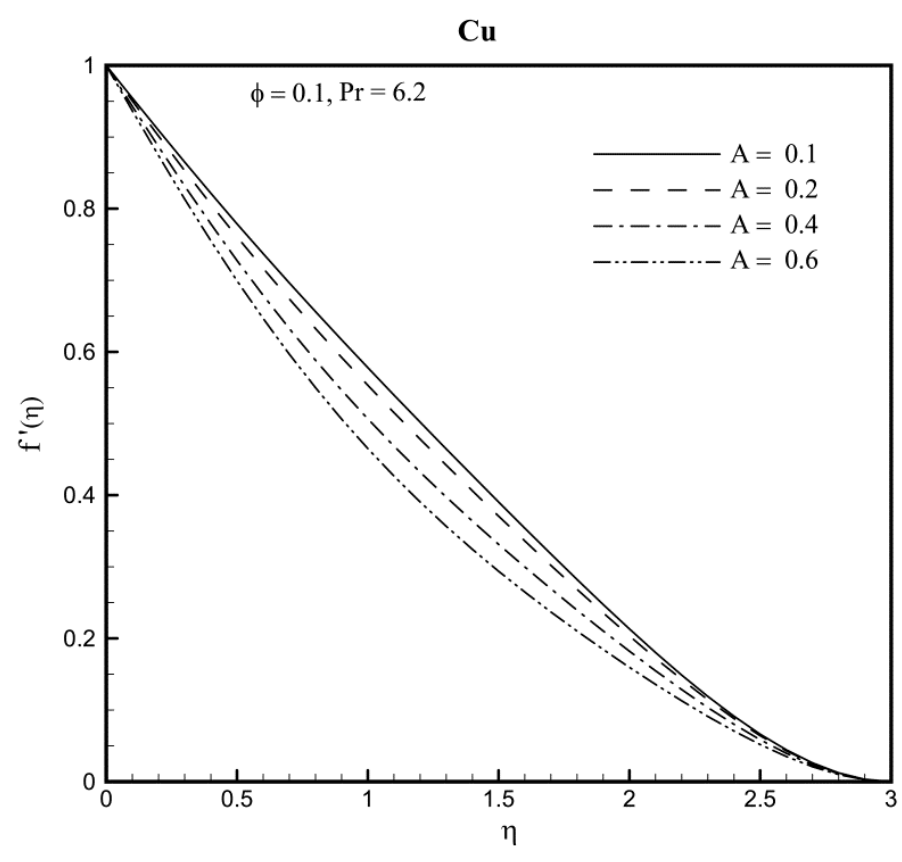

(a)

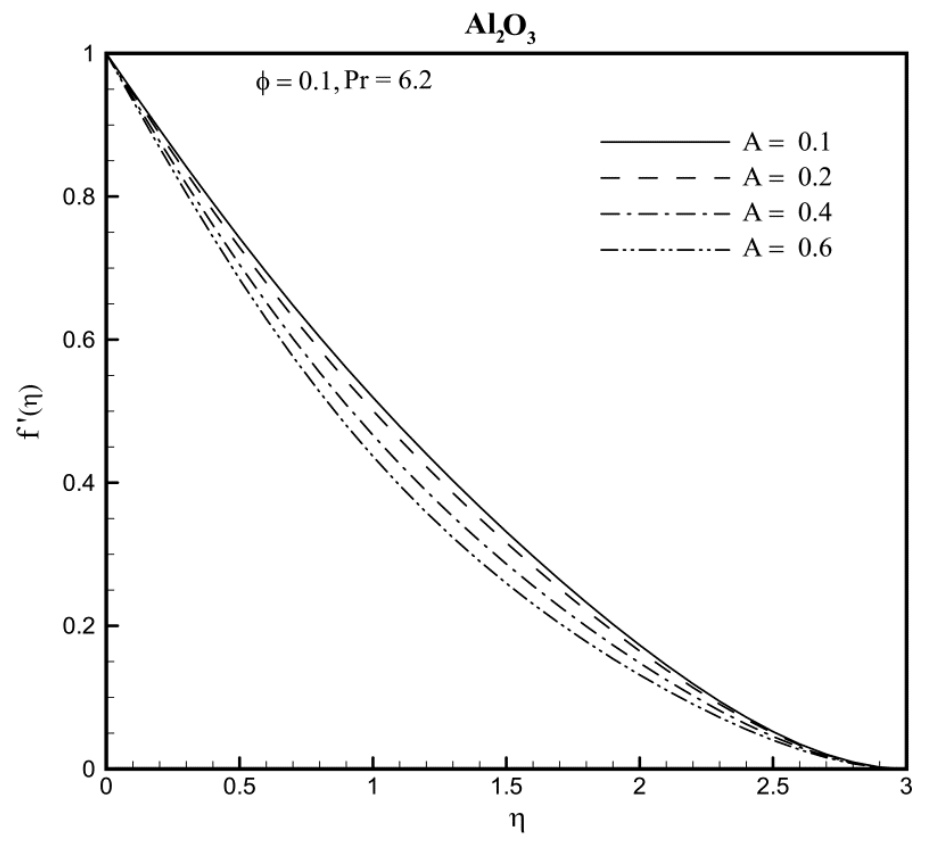

(b)

Figure 4a, b. Simulated velocity profiles for various values of stretching parameter when $E c=$ $1.0, \beta=1.0, M=1.0, \lambda=1.0$.

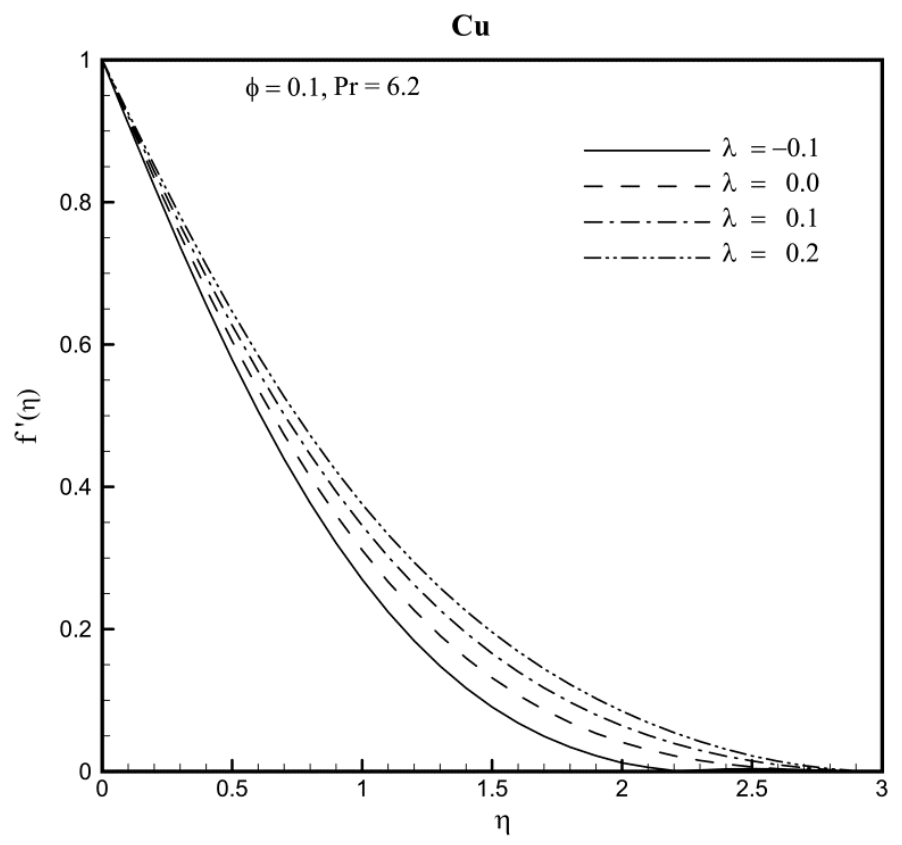

(a)

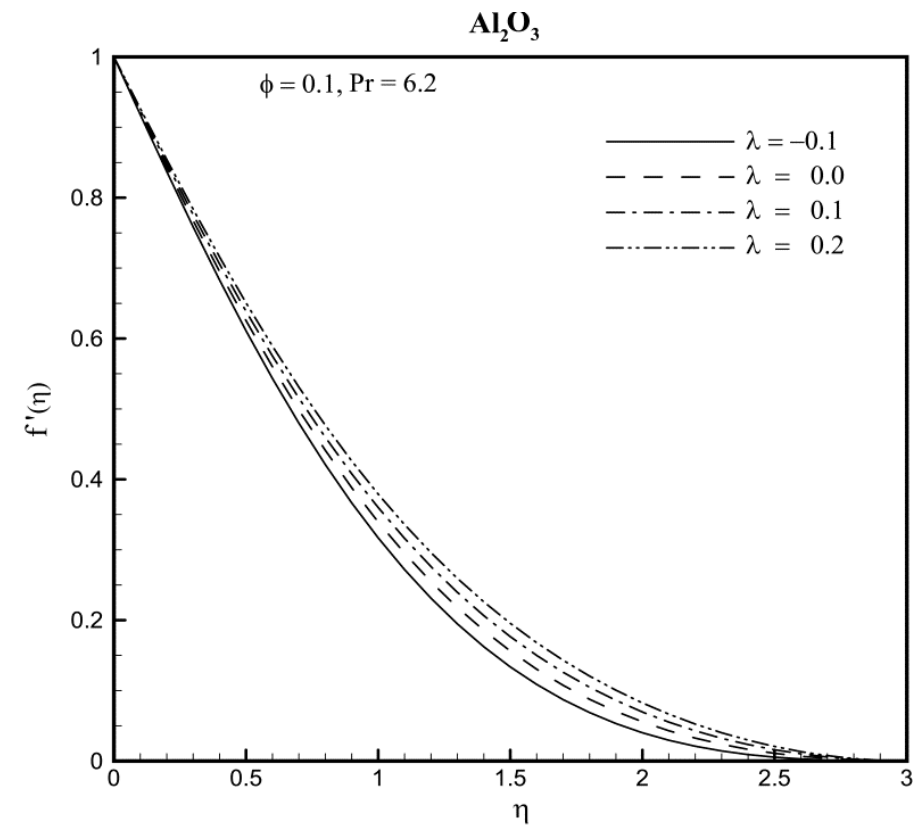

(b)

Figure 5a, b. Simulated velocity profiles for various values of convection parameter when $E c=$ $1.0, \beta=1.0, M=1.0, A=0.2$. 


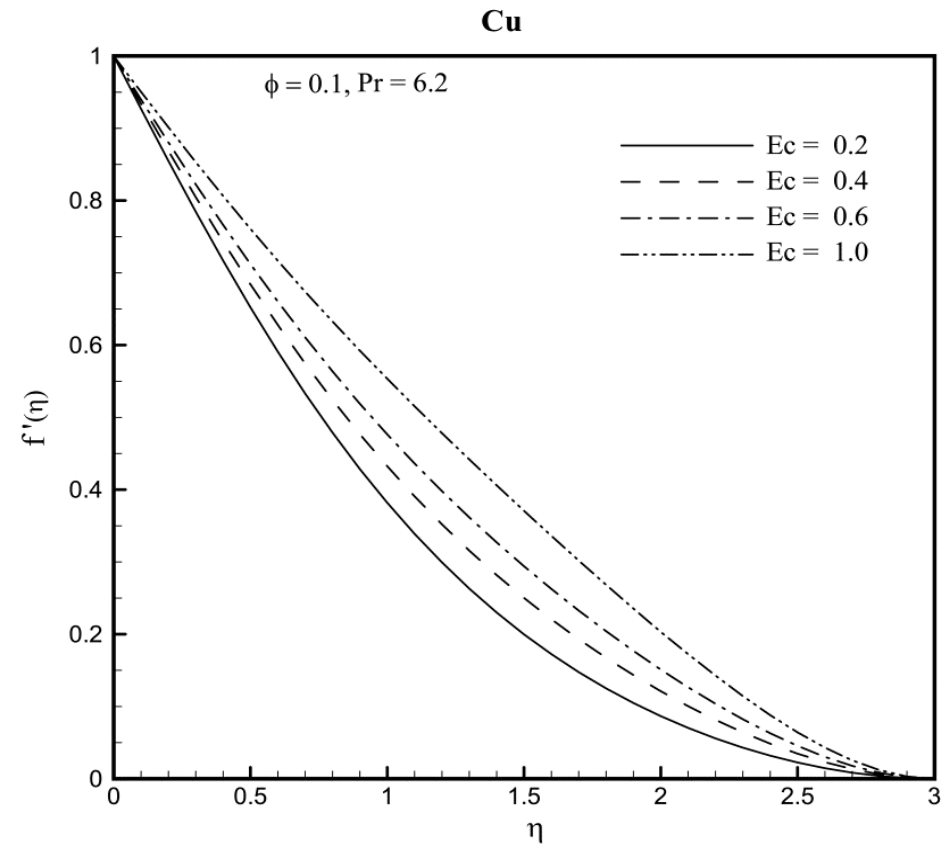

(a)

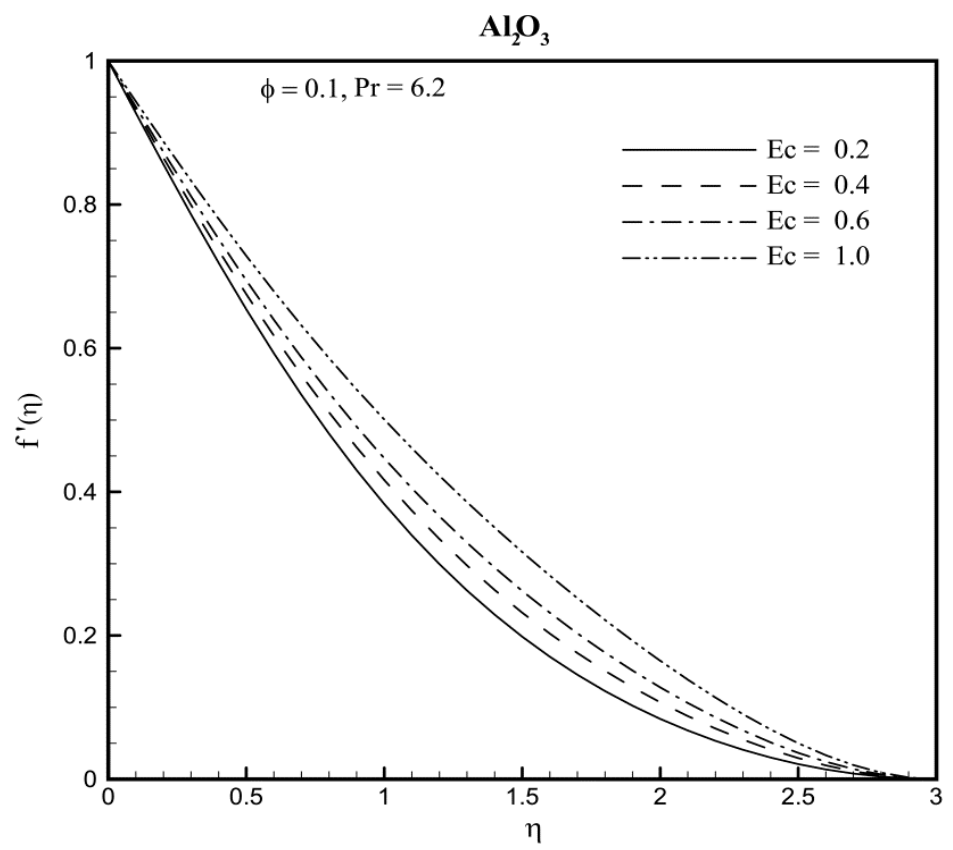

(b)

Figure 6a, b. Simulated velocity profiles for various values of Eckert number when $\lambda=1.0, \beta=$ $1.0, M=1.0, A=0.2$.

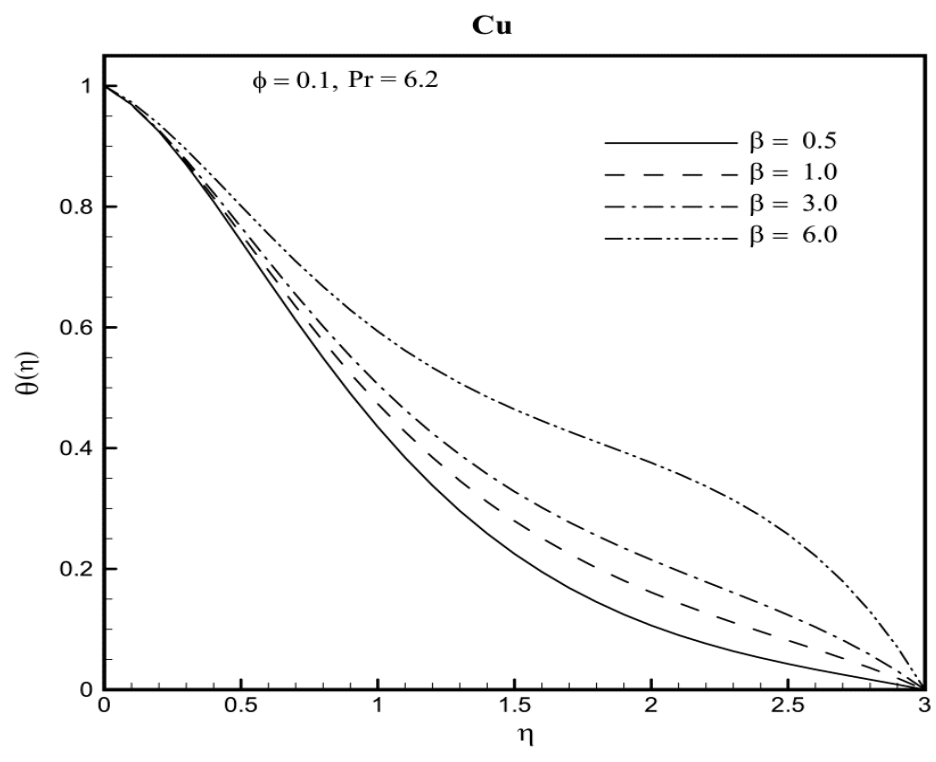

(a)

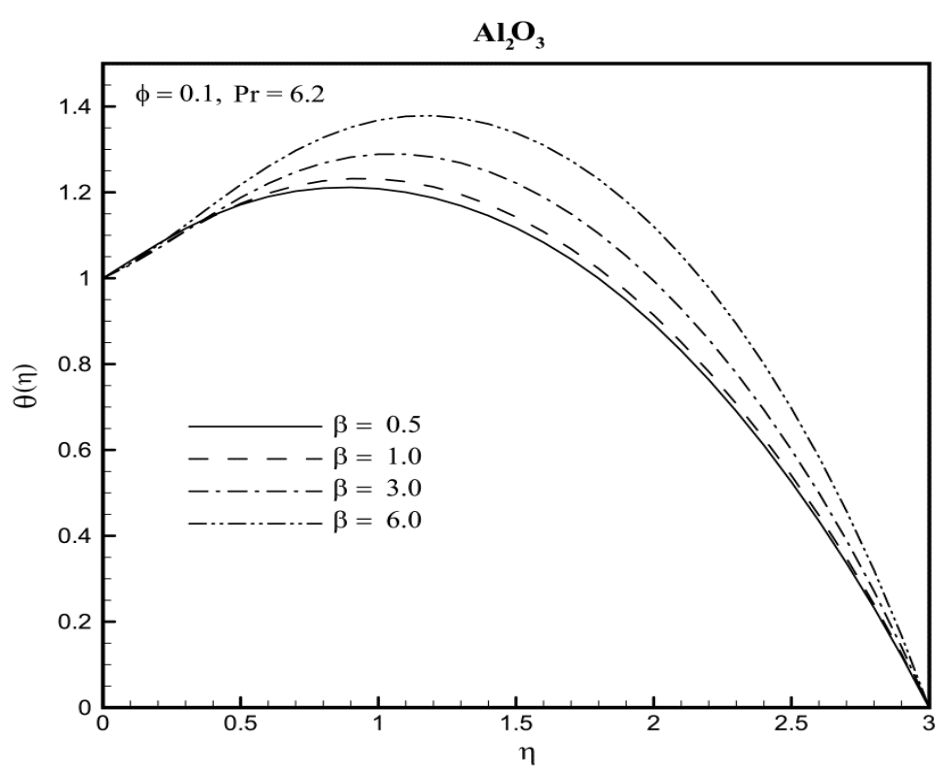

(b)

Figure 7a, b. Simulated temperature profiles for various values of couple stress parameter when $E c=1.0, M=1.0, A=0.2, \lambda=1.0$. 


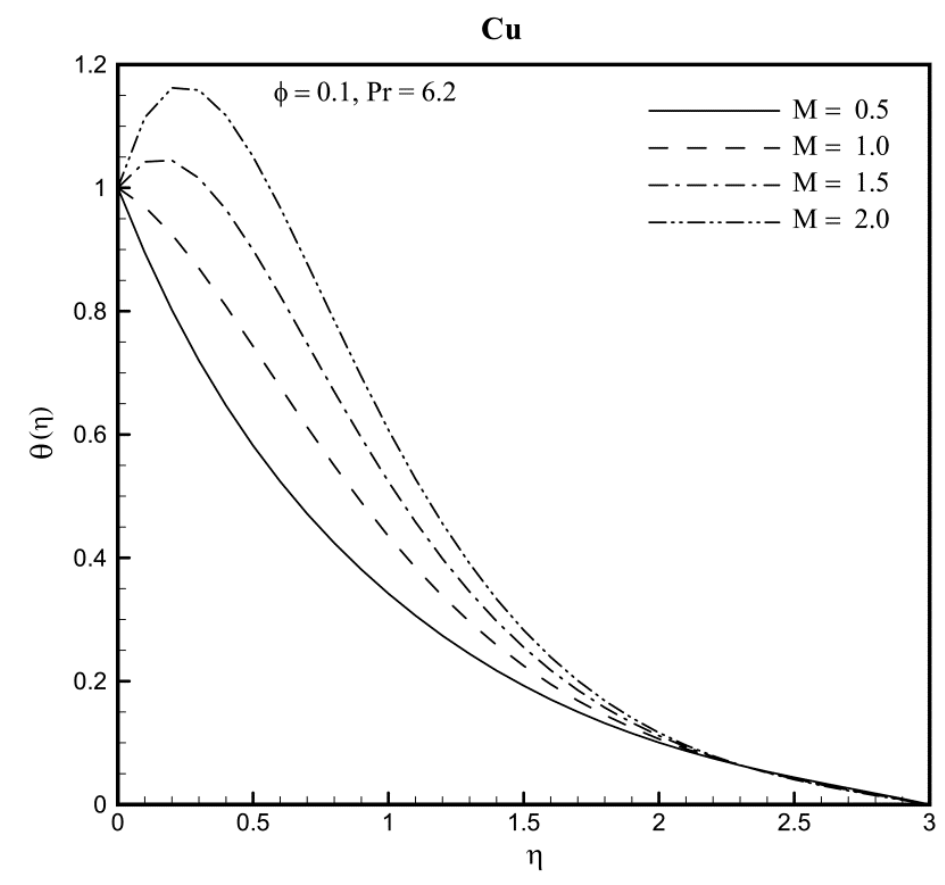

(a)

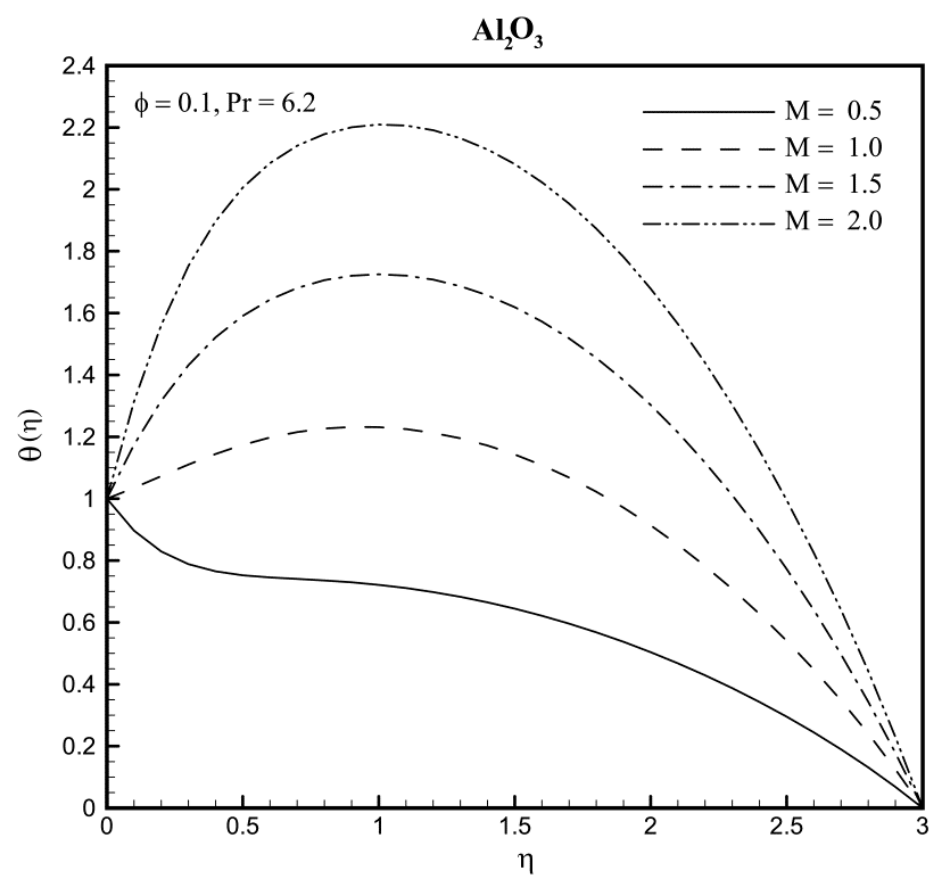

(b)

Figure 8a, b. Simulated temperature profiles for various values of magnetic parameter when $E c=$

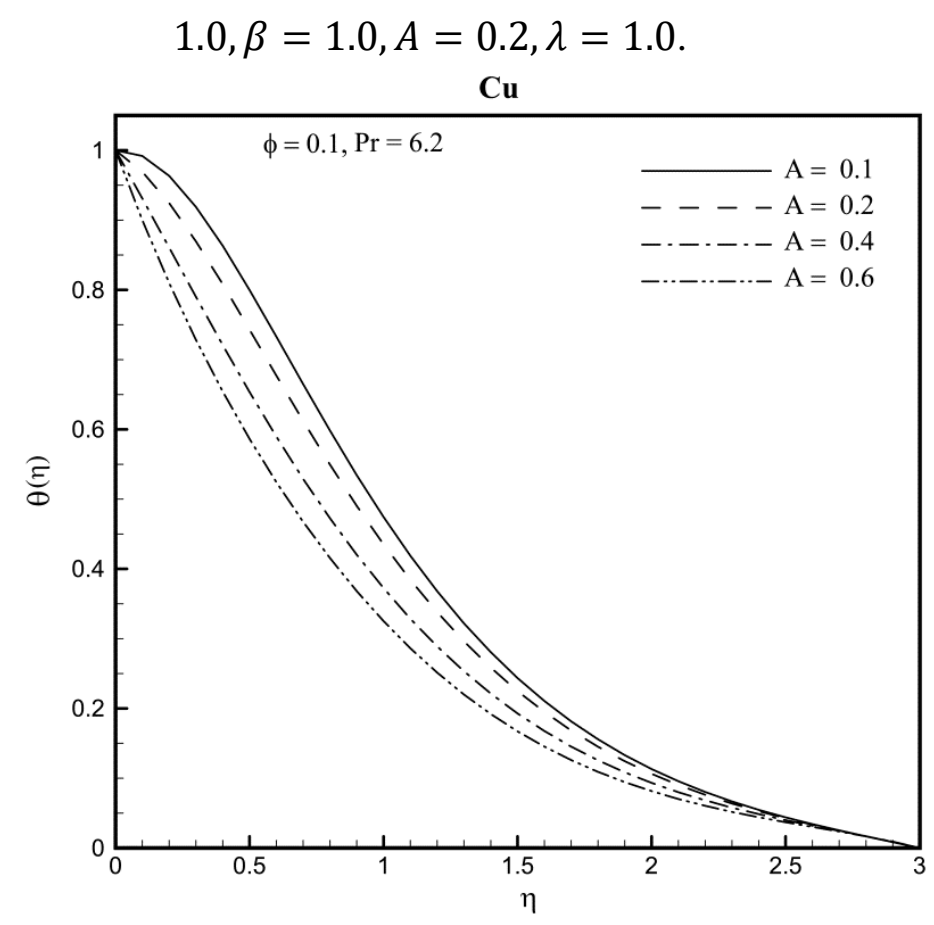

(a)

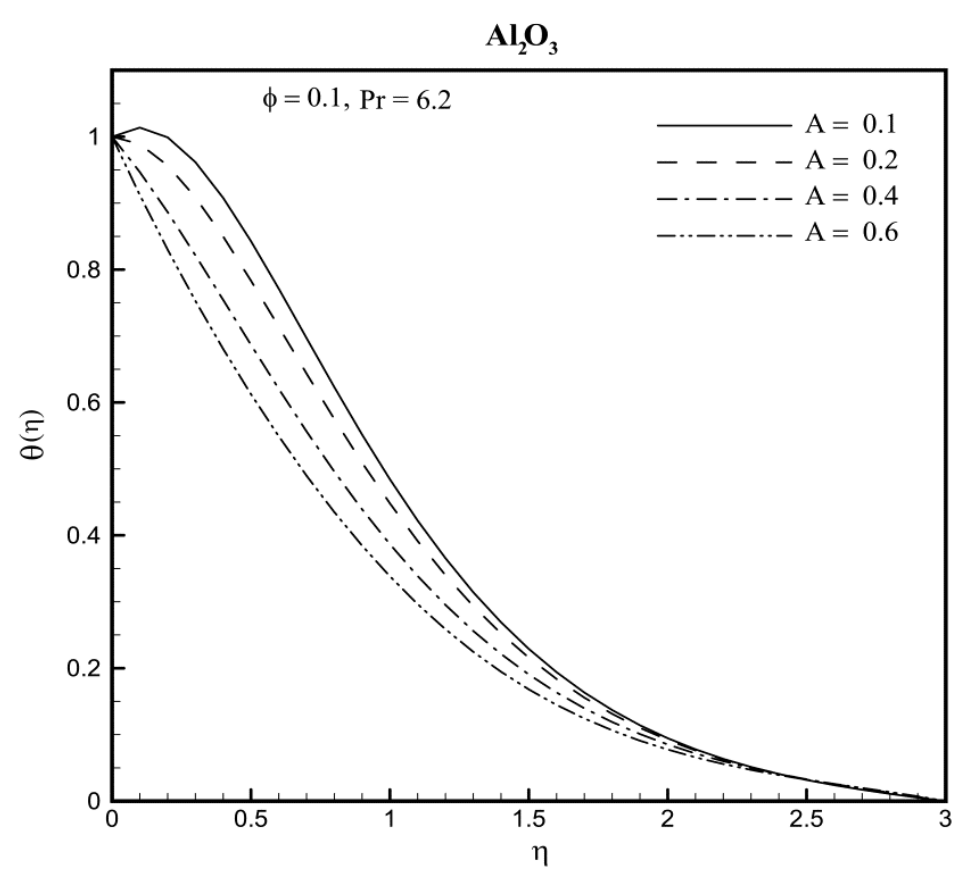

(b)

Figure 9a, b. Simulated temperature profiles for various values of stretching parameter when $E c=$ $1.0, \beta=1.0, M=1.0, \lambda=1.0$. 


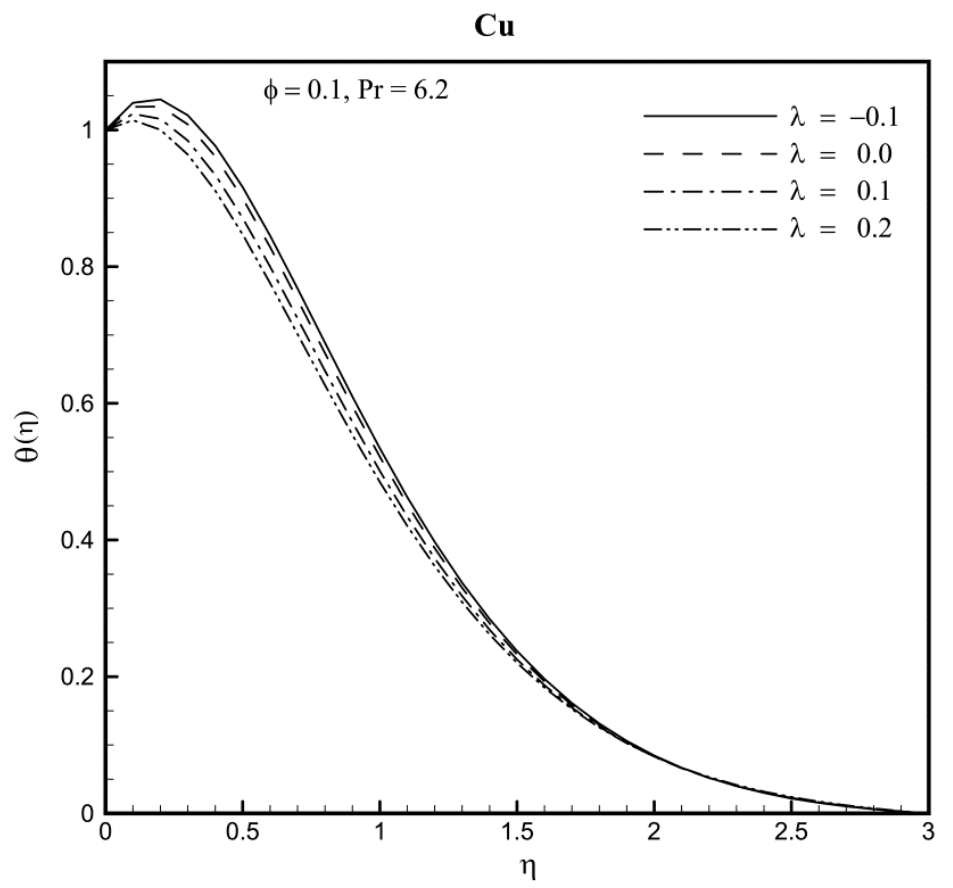

(a)

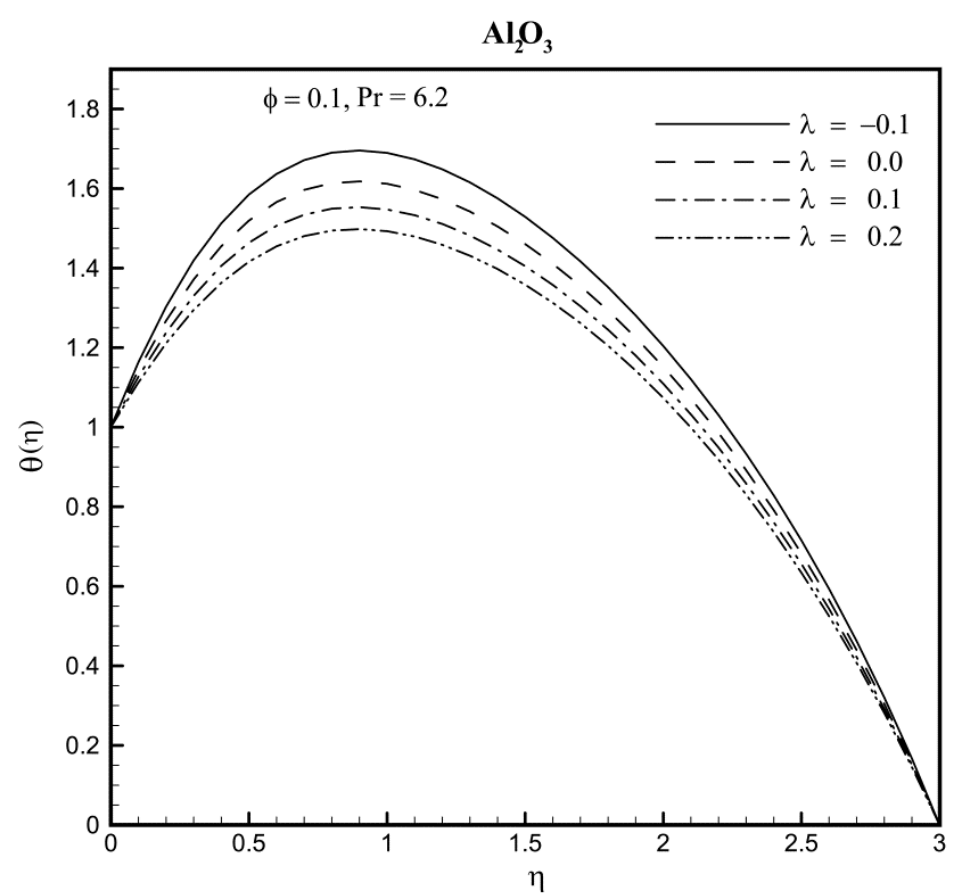

(b)

Figure 10a, b. Simulated temperature profiles for various values of convection parameter when $E c=$ $1.0, \beta=1.0, M=1.0, A=0.2$.

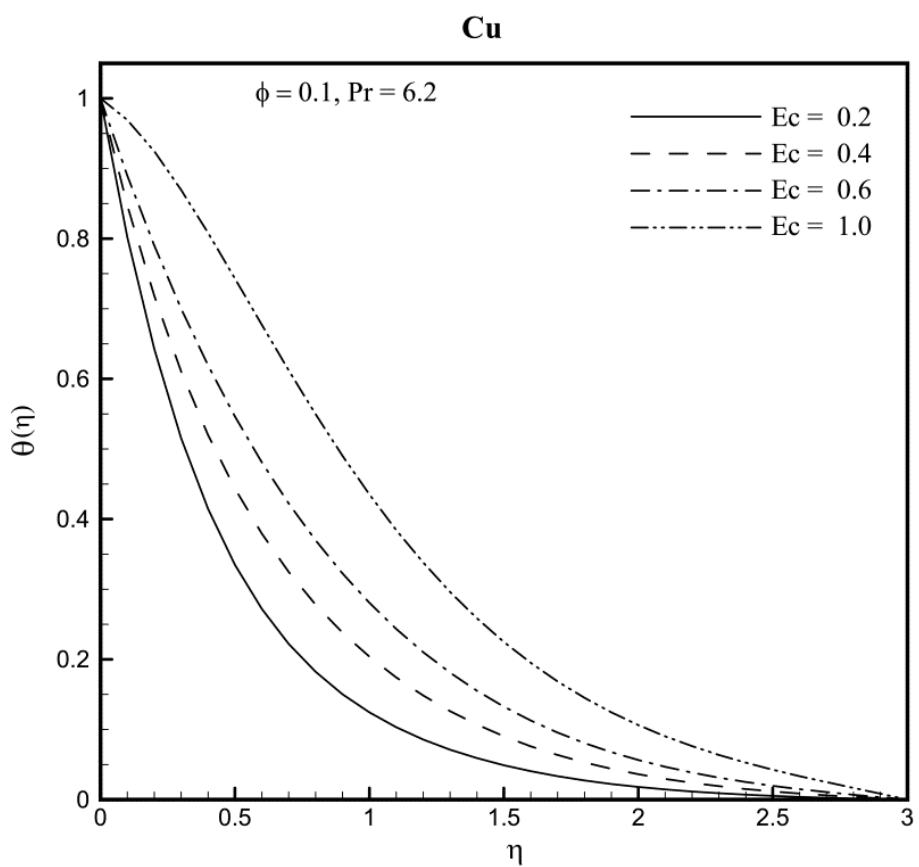

(a)

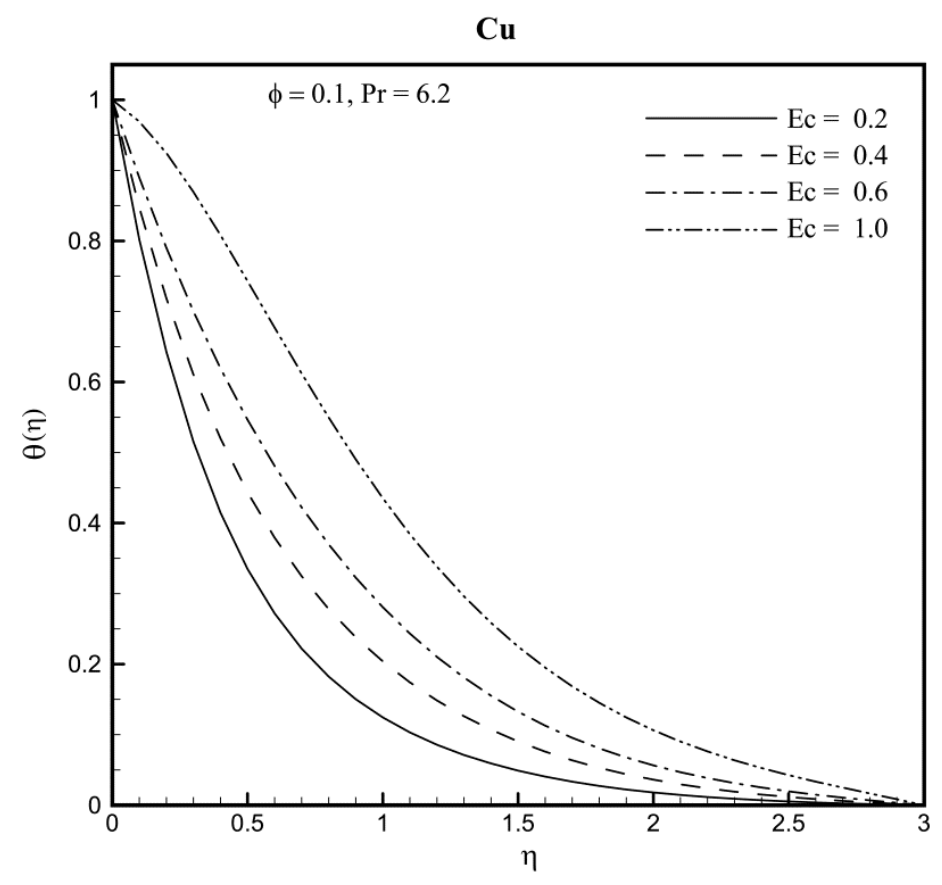

(b)

Figure 11a, b. Simulated temperature profiles for various values of Eckert number when $\lambda=$ $1.0, \beta=1.0, M=1.0, A=0.2$. 


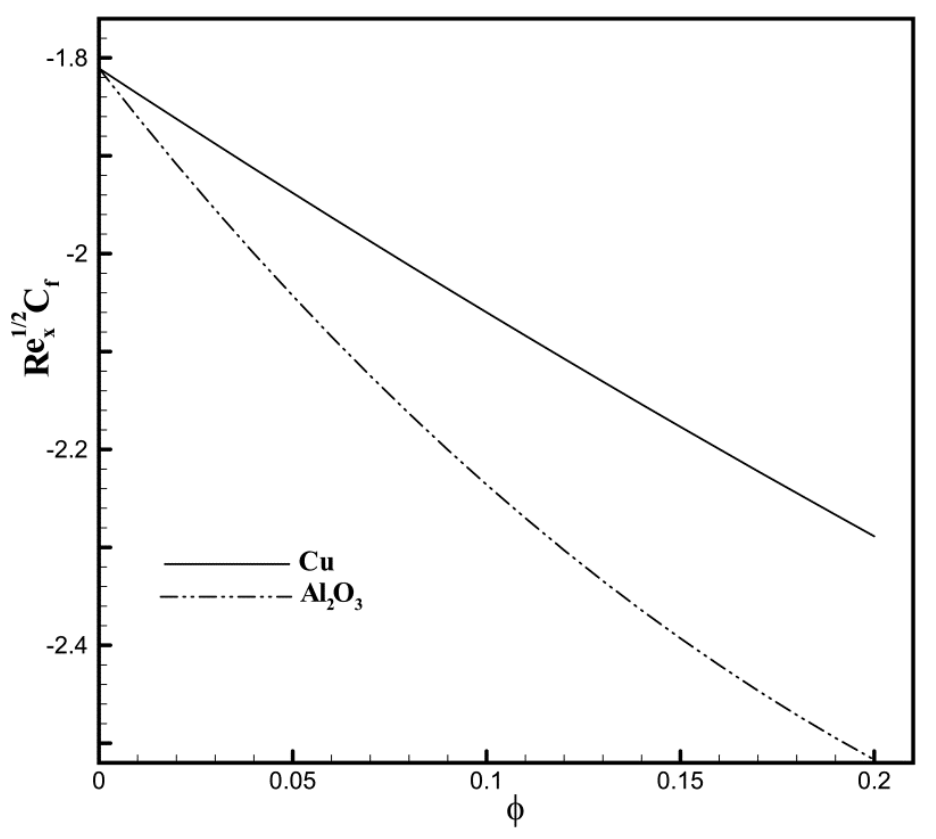

(a)

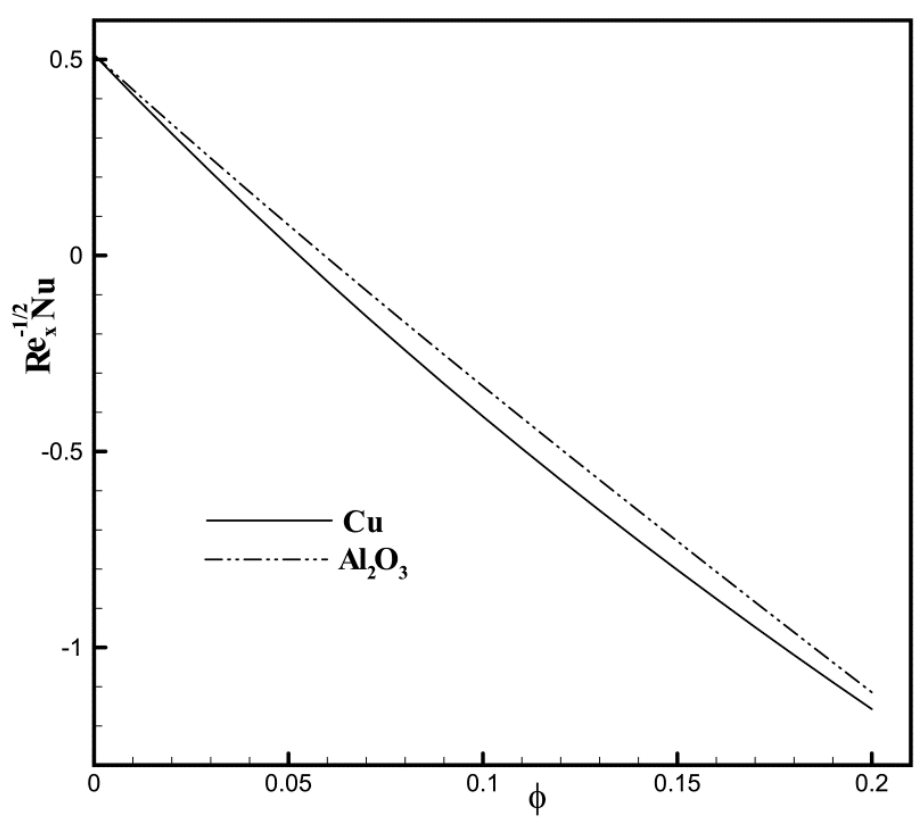

(b)

Figure 12a, b. Simulated skin friction coefficient and Nusselt number profiles versus volume fraction ( $\phi$ ) for different nano-particles when $\lambda=0.1, \beta=1.0, M=1.0, A=0.2, E c=1.0, \operatorname{Pr}=6.2$. 